Florida International University FIU Digital Commons

\title{
The effect of food safety education on the knowledge attitude and behavior of foodservice workers of inner city public schools
}

Lillian Craggs-Dino

Florida International University

DOI: $10.25148 /$ etd.FI14061535

Follow this and additional works at: https://digitalcommons.fiu.edu/etd

Part of the Dietetics and Clinical Nutrition Commons

\section{Recommended Citation}

Craggs-Dino, Lillian, "The effect of food safety education on the knowledge attitude and behavior of foodservice workers of inner city public schools" (2002). FIU Electronic Theses and Dissertations. 2655.

https://digitalcommons.fiu.edu/etd/2655 
FLORIDA INTERNATIONAL UNIVERSITY

Miami, Florida

THE EFFECT OF FOOD SAFETY EDUCATION ON THE KNOWLEDGE, ATTITUDE AND BEHAVIOR OF FOODSERVICE WORKERS OF INNER CITY PUBLIC SCHOOLS

\author{
A thesis submitted in partial fulfillment of the \\ requirements for the degree of \\ MASTER OF SCIENCE \\ in \\ DIETETICS AND NUTRITION \\ by \\ Lillian Craggs-Dino
}


To: Dean Ronald M. Berkman

College of Health and Urban Affairs

This thesis, written by Lillian Craggs-Dino, and entitled The Effect of Food Safety Education on the Knowledge, Attitude and Behavior of Foodservice Workers of Inner City Public Schools, having been approved in respect to style and intellectual content, is referred to you for judgment.

We have read this thesis and recommend that it be approved.

Fatma Huffman

Penny Parham

Zisca Dixon, Major Professor

Date of Defense: June 28, 2002

The thesis of Lillian Craggs-Dino is approved.

Dean Ronald M. Berkman College of Health and Urban Affairs

Dean Douglas Wartzok University Graduate School

Florida International University, 2002 


\section{DEDICATION}

I would like to dedicate this thesis to the memory of my mother who has been my guardian angel throughout my life.

I would also like to dedicate this thesis to my husband, Steven and sister, Kim. Their patience, encouragement, support and love have brought me to this day. I could not have done it without both of you. Words cannot express my gratitude. I love you both with "all who I am". 


\section{ACKNOWLEDGMENTS}

I would like to sincerely thank the members of my committee, Dr. Fatma Huffman and Ms. Penny Parham for their support, guidance and wisdom. Dr. Huffman, as always, has inspired me to reach for the stars and it is her never-waning encouragement that gave me the strength to do so. It has been an honor to learn from her, and I am proud to call her a mentor.

Ms. Parham was instrumental in generating ideas used for this research study. Without her willingness and her commitment to contribute, this study would have never been completed.

I would like to express my gratitude to Dr. Zisca Dixon, my major professor, for her patience, dedication and personal interest in showing me how to be the best I can be. Dr. Dixon has contributed to both my intellectual and academic well being by allowing me to explore all of my potential. I truly enjoyed and will always be graciously appreciative of the experiences and opportunities that she has given me.

Lastly, I would like to thank the Miami-Dade County Public School Board and the foodservice employees of Miami-Dade County Public Schools for permitting this research study to move forward. 


\begin{abstract}
OF THE THESIS
THE EFFECT OF FOOD SAFETY EDUCATION ON THE KNOWLEDGE, ATTITUDE AND BEHAVIOR OF FOODSERVICE WORKERS OF INNER CITY PUBLIC SCHOOLS
\end{abstract}

by

Lillian Craggs-Dino

Florida International University, 2002

Miami, Florida

Professor Zisca Dixon, Major Professor

The purpose of this study was to determine if food safety education influences food safety knowledge, attitude and behavior among inner city public school foodservice employees. Knowledge, attitude and behavior of an experimental group $(n=22)$ was assessed before and after 3 -hour food safety training and compared with a control group $(n=10)$ that received no food safety training. We hypothesized that those who received food safety training would have improved knowledge, attitude and behavior towards food safety issues compared to those who did not receive training.

Results showed that food safety training significantly increased $(p<0.001)$ the knowledge of foodservice employees compared to those who didn't receive the training. However, the 3-hour training did not significantly influence attitude or practice of safe food-handling techniques. Education and consistent re-training, coupled with Hazard Analysis and Critical Control Point (HACCP) system, food-handler sanitation certification and frequent supervision may help to increase food safety awareness among foodservice employees. 


\section{TABLE OF CONTENTS}

CHAPTER

PAGE

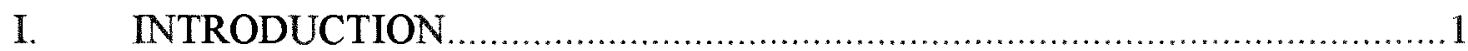

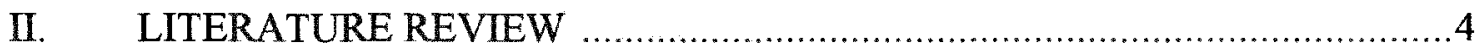

A. Food Borne Illness Surveillance Data ................................................4

B. The Link Between Food Handler and Food Borne Disease ...................8

C. Food Safety Knowledge Gap ........................................................14

D. Food Safety Knowledge, Attitude and Behavior of

Foodservice Employees................................................................ 18

E. The Effectiveness of Food Safety Education and

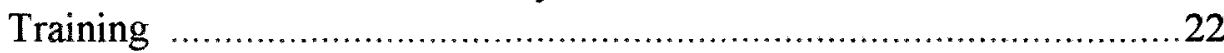

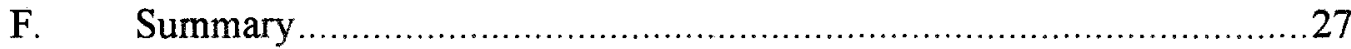

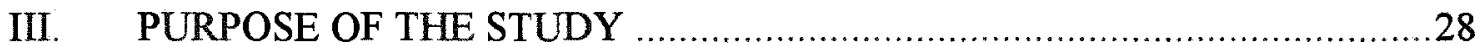

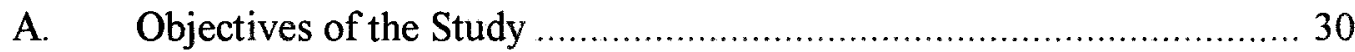

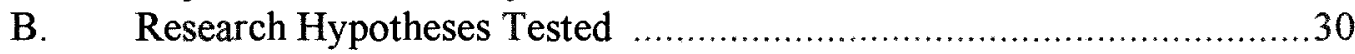

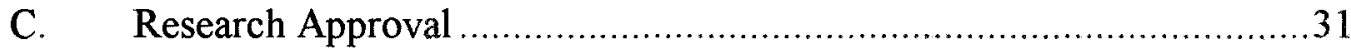

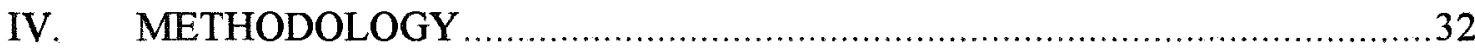

A. Subjects and Incentive to Participate …..............................................

B. Data Collection Modules ............................................................... 33

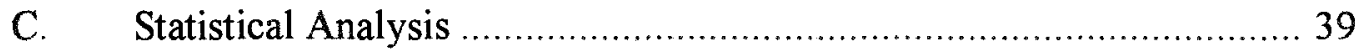

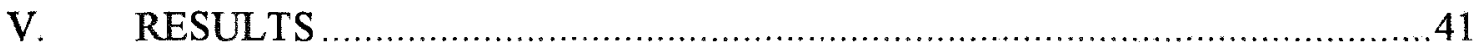

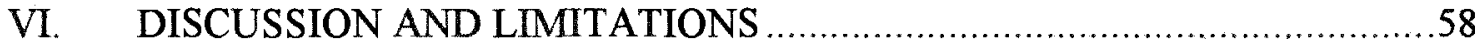

VII. CONCLUSIONS AND RECOMMENDATIONS …................................... 65

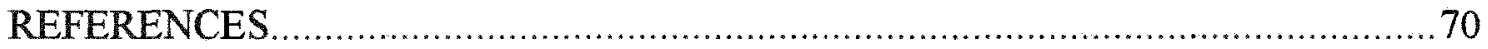

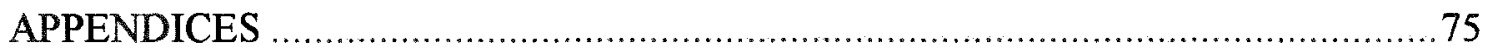




\section{LIST OF TABLES}

TABLE

PAGE

Table 1: Socio-Demographic Characteristics

Table 2: $\quad$ Response To Question Regarding Food Safety Training.

Table 3: $\quad$ Mean Food Safety Knowledge Scores and Knowledge Gain

Table 4: $\quad$ Mean Food Safety Attitude Scores and Attitude Change 49

Table 5: $\quad$ Mean Food Safety Behavior Scores and Behavioral Change. 51

Table 6: Number of Schools That Showed Improved Facility Inspection 53

Table 7: Number of Schools That Did Not Show Improved Facility Inspection..... 55

Table 8: Food Safety Training In-Service Evaluation 57 


\section{Chapter I}

\section{Introduction}

Despite newly focused attention and awareness of food borne illness and its etiology, food borne disease outbreaks continue to pose a threat to the American public (1). Food rendered unsafe for consumption may be caused by such hazards as physical, chemical or biological means, whereby biological hazards pose the greatest source for contamination and cause of illness. Biological contamination includes those of microbial origin such as yeast, molds, parasites, viruses and bacteria (2). Those especially susceptible to disease and complications from food borne pathogens are the immunocompromised, either caused by disease status or age, the elderly, infants and children (3).

Research shows that a wide variety of these pathogenic microorganisms can cause food borne diseases and are directly associated with improper foodservice operations such as poor food-handling, temperature abuse in terms of preparation, storing, cooking, holding and serving, as well as poor personal hygiene practices of the food handler (4). There is a positive correlation between food borne disease outbreak with that of the hygienic status of the food handler (5-8). Existence of serious food safety knowledge gaps can be found among both the general public and foodservice professionals (9-14). Inconsistent or nonexistent on-the-job food safety training is today's reality in many foodservice operations. The due diligence of food safety relies on adequate training and continuing education of the persons responsible for handling and serving food. Due to shifts in demographics, lifestyle changes, lack of leadership and high turnover rates seen in institutional foodservice, prevention of food borne illness is further complicated (15-17). Research shows the need for effective intervention and food safety 
training programs to decrease risk of food borne disease outbreak (18-20). Positive changes in knowledge and attitude have been correlated to positive behavioral change (21-26). Research shows that creative and consistent education and training increases knowledge (27-29). Acquiring a positive attitude towards practicing food safety techniques and management support also plays an active role in preventing food borne disease outbreaks $(18,21,30)$. Food borne disease outbreak is not caused by a single entity, but rather an accumulation of many factors such as those discussed above.

In reference to these issues, a convenience sample of foodservice workers employed at public schools located in inner city Miami-Dade County, Florida were chosen for this study for several reasons. First, research has shown that the majority of food borne illness outbreaks was caused by foods prepared in institutionalized foodservice by food handlers (4). Given that school aged children are particularly susceptible to illness and mortality from food borne pathogens (3) and may consume foods prepared in institutionalized public schools, this research study focused attention on these foodservice facilities. Secondly, inner city Miami-Dade County public schools were chosen for this study because the majority of the foodservice employees of these schools were able to speak, read and write in English. This was crucial since the researchers were not bilingual, and all of the material utilized in this study, including the pre-post-test and in-service training educational material was in English. Lastly, the public schools located in inner city Miami-Dade County were chosen and approved for participation in this study by the Director of Operations of Regions I, II and III of the Department of Food and Nutrition of Miami-Dade County Public Schools and by the Miami-Dade County Public School Board. 
The purpose of this study was to determine the level of food safety knowledge, attitude and behavior among inner city school foodservice employees, and to determine if food safety education was needed to properly train those who are responsible for serving safe food in the public schools.

\section{Research Questions}

1. What level of food safety knowledge do inner city school foodservice employees possess?

2. How much, if any, food safety training exists for these employees?

Furthermore, what is the extent and consistency of this training?

3. What are the attitudes towards practicing food safety procedures among inner city school foodservice personnel?

4. Is food safety behavior influenced by level of knowledge and training?

5. Is food safety behavior influenced by food safety attitude? 


\section{Chapter II}

\section{Literature Review}

The following review of literature examines current data of food borne illness outbreaks in the United States and its etiology. The link between food borne illness with that of the practices of the food handler is shown. Positive correlation between lack of knowledge and improper training is addressed. A synopsis of how food safety education influences the knowledge and due diligence of the food handler is reviewed.

\section{A. Food Borne Illness Surveillance Data}

Although the American food supply is considered among the safest in the world, many individuals are stricken with illness caused by the foods consumed. According to statistics compiled by the Partnership for Food Safety Education (1) it is estimated that as many as 9,000 deaths and 6.5 to 33 million illnesses in America are directly linked to eating contaminated foods containing food borne pathogens, costing an estimated \$6.5$\$ 34.9$ billion dollars. Pathogenic microorganisms account for $90 \%$ of these illnesses. Present estimates indicate that one in ten Americans experience some sort of food borne illness each year. The Centers for Disease Control and Prevention (CDC) have estimated this number to be as high as 76 million persons who have experienced food borne illness (1). However, these numbers may be greatly underestimated due to underreporting, thus food borne disease is still presently a threat to even the most industrialized country in the world, the United States. Among those population groups at greatest risk of serious illness and mortality from food borne enteric microorganisms are infants, children, the elderly, pregnant women, the immuno-compromised and those persons with limited 
resources or access to medical attention, such as persons with low socioeconomic status (3).

Since 1973 to the present, the CDC has maintained a collaborative surveillance program for periodic reporting on the occurrence and causes for food borne disease outbreaks (FBDO) in the United States. The surveillance program is maintained through The Food Borne Diseases Active Surveillance Network (FoodNet). FoodNet is a component of the CDC's Emerging Infections Program (EIP), and it is a collaborative effort between the CDC, U.S. Department of Agriculture (USDA) and the Food and Drug Administration (FDA). FoodNet was established in various counties of California, Connecticut and Georgia and the entire states of Minnesota and Oregon. In 1995 and 1997, respectively, Maryland and New York were added. Olsen et al (2) presents a summary of this epidemiological surveillance data for the reporting period 1993-1997. Bacterial pathogens caused the largest percentage of outbreaks and largest percentage of cases at $75 \%$ and $86 \%$, respectively. Within this reporting period, there were a total of 2,751 outbreaks, which caused 86,058 persons to become ill. Salmonella enteriditis accounted for 357 of the 655 bacterial FBDO, and caused the largest number of outbreaks, cases and deaths, followed by chemical agents, viruses and parasites. However, although food borne diseases are fairly common, most are sporadic and thus, only a fraction of these cases are reported to the CDC. For example, Salmonella infection causes an estimated 1.4-million food borne illnesses annually, however, during the reported period 1993-1997, only 189,304 were reported through the FBDOSurveillance System. The surveillance data, however, provided an indication of etiologic agents, mode of transmission and directed public health officials to take action on 
preventing outbreaks of food borne disease. It was concluded in this summary that although the annual number of FBDO reported to the CDC hadn't substantially changed from previous years, it was found that Salmonella enteriditis continued to be the major cause of illness and death. Escherichia coli (0157:H7) was also implicated in multi-state outbreaks prominent in contaminated produce.

The Centers for Disease Control and Prevention publishes findings of its Emerging Infections Program Food borne Diseases Active Surveillance Network (FoodNet) in the Morbidity and Mortality Weekly Report (MMWR). In MMWR Special Report on Selected Notifiable Diseases in the United States (31) the total reported cases of salmonellosis in 1994 were 43,323, followed by Escherichia coli (0157:H7) infection at 1,420 and botulism at 143. A preliminary report from FoodNet data compiled for 1999 in MMWR (32) showed that 10,697 laboratory-confirmed cases were identified to be: 4,533 of salmonellosis, 3794 of campylobacteriosis, 1031 of shigellosis, $530 \mathrm{E}$. coli (0157:H7) infections, 474 of cryptosporidiosis, 163 of yersiniosis, 113 of listeriosis, 45 vibriosis, and 14 cyclosporiasis. This surveillance covered a population of approximately 25.6 million persons (about $9 \%$ of the United States population), whereby incidence per 100,000 was highest for salmonellosis and campylobacteriosis and shigellosis. Although surveillance data for this reported period showed a decline in campylobacteriosis when compared to data compiled in 1996-1998, salmonellosis increased in all FoodNet sites. Norwalk-like viruses (NLV) are the most common cause of gastroenteritis resulting in 23 million illnesses annually. To date, NLV is the most prevalent cause of food borne illness caused by a viral pathogen in the United States (33). Surveillance data showed an increase in NLV, which attributed to a major outbreak in Alaska and Wisconsin. Food 
borne transmission and person-to-person contact were implicated in $37 \%$ and $20 \%$ of the outbreaks, respectively.

In a comparative preliminary report of food borne illnesses reported for the year 2001 by the CDC's FoodNet (34), it is estimated that incidence of illness continues to be high especially in infants and children. Preliminary findings indicate that although incidence of yersiniosis, listeriosis, campylobacteriosis and salmonellosis has declined in adults, campylobacteriosis and salmonellosis appear to be on the rise in children. In light of this new data, FoodNet has initiated a case-controlled study of sporadic salmonellosis and campylobacteriosis in children, however, this report has not yet been published.

The findings of the surveillance data are subject to several limitations. First, data compiled in these surveillances represent a small percentage of the United States population and the geographical areas chosen may not be representative of the nation as a whole. Second, data compiled is limited to laboratory-confirmed cases, thus does not take into account the millions of unreported cases of food borne illnesses, which actually occurred for that reported period. According to Bryan et al (35) only about $10 \%$ of the outbreak cases of enteric illness caused by food borne pathogens are identified by health agencies. Variations of testing within laboratories may cause this discrepancy of reported findings. However, this surveillance is both necessary and crucial in providing information to alert public health officials and those responsible for feeding the consumer. Even if the CDC grossly overestimates numbers of those who have experienced food borne illness at 76 million, (1) any number of illnesses presented is still a major cause for concern and should facilitate the development of educational efforts to promote the food safety initiative. Food safety education is a key component of the food 
safety initiative. Surveillance data also facilitates changes on varying levels of food production, from farm to table. Data also allows for the continued monitoring of new and emerging pathogens, as well as keeping at bay present knowledge of existing pathogens. Ultimately, surveillance data provides a statistical background, which may serve as the basis for reform and control from outbreaks of food borne disease.

\section{B. The Link Between Food Handlers and Food Borne Disease}

According to the CDC Surveillance Summaries (36) the two most commonly reported food preparation practices that contributed to outbreaks of food borne disease are improper holding temperature and poor personal hygiene of the food handler. Section 103 (d) of the Americans with Disabilities Act (37) directs the Secretary of Health and Human Services to identify, publish and annually review a list of pathogens and communicable diseases that are transmitted through handling of food and contaminated by food handlers, either directly or indirectly. This list of pathogens, which is updated annually, can be found in the Federal Register (38), which is published by the CDC. According to the Federal Register (38) the most commonly transmitted pathogens from food handlers are Salmonella typhi, Shigella, Staphylococcus aureus, Streptococcus pyogenes, the Hepatitis A virus, and the Norwalk-like virus. Food handlers who fail to wash their hands after restroom usage, who are infected via skin lesions or respiratory or gastrointestinal infections and continue to handle food, commonly transmit these pathogens. In addition, improper holding temperatures allow these pathogens to multiply to toxic levels (>10 particles). According to Section 103 (d) of the Americans with Disabilities Act (37) food handlers who have infectious and/or contagious diseases by 
pathogens found on the list from the Federal Register (38) may be removed from a foodhandling to a non-food-handling job. However, this is not the case seen in many foodservice institutions. With current job downsizing, the hiring of unskilled labor, poor on-the-job training, the lack of incentives and high turnover, food handlers continue to have the responsibility of preparing and serving food, however without being held responsible of serving it free of food borne pathogens. In many cases, poor foodhandling behaviors on the part of foodservice employees have been directly responsible for food borne disease outbreak (4-8). Bean et al (39) found that $79 \%$ of implicated food was prepared in commercial or institutional establishments.

In a review conducted by Levine et al (4) of the outbreaks reported to the CDC during 1975 to 1987, twenty-six states reported 115 outbreaks of food borne diseases in institutional nursing homes. Salmonella enteriditis was the culpable microbe and accounted for $52 \%$ and $81 \%$ of outbreaks and deaths, respectively. According to the Food Safety and Inspection Service (FSIS) (40) S. enteriditis outbreaks may be directly attributed to cross contamination during food preparation. In a report by the CDC (41), of the $41 \%$ reported outbreaks in $1994,79 \%$ were traced back to bacterial pathogens, where $60 \%$ was traced to salmonella species. Staphylococcal diseases were the next most identified cause of food borne illness, accounting for $23 \%$ of outbreaks.

In a cohort study conducted by Olson et al (5) Staphyloccocal poisoning was evident in 25 of 110 persons who ate at a church fund-raiser in New Mexico. The New Mexico Department of Health (NMDOH) was notified, and epidemiological, bacteriologic and environmental evidence suggested that the taco meat was contaminated with Staphyloccocus aureus. Staphyloccocal isolates were both enterotoxigenic and 
preformed endotoxin was detected in the food sample. Through questionnaires, it was discovered that all the food prepared for the fund-raiser was by four women in their respective homes. Although it was not determined how $S$. aureus was introduced into the taco meat, questionnaires revealed that one of the batches of taco meat was prepared the night before and was left uncovered at room temperature for four hours before being refrigerated. It was concluded that the four-hour period in which the taco meat was held at room temperature was ample time for $S$. aureus to multiply and produce enterotoxin. This batch was then brought to the fund-raiser, reheated and kept warm in an electric roaster until it was served. High levels of enterotoxigenic organisms were found, along with heat altered entertoxin in this first batch. A sample from a second batch of taco meat, which had been held in the refrigerator, never reheated or used, didn't contain S. aureus. Upon questioning, all the food handlers denied having cuts or sores or any illnesses at the time of preparation. Gloves were not used in preparing or serving the food. Although stool samples taken from the food handlers did not contain the implicated pathogen, the samples were taken three days after the fund-raiser, and may not have been shedding in the stool. No samples were taken from the nose, throats or hands although it is found that thirty to fifty percent of healthy humans carry Staphylococcus aureus naturally, and can be transmitted by a cough, sneeze or touch from an infected person. This case represents a common cause for food borne outbreaks: improper temperature in the cooling and holding of the food, and possibly the personal hygiene of the food handler.

Food borne gastroenteritis caused by viruses passed from food handler has become a major public health concern. The most common etiological viral agents 
associated with food borne disease outbreak are attributed to the Norwalk and Norwalklike virus (NLV), the Snow Mountain Agent virus (SMA) and Hepatitis A virus (HAV). Foods contaminated by an ill food handler may be implicated as the vector. Norwalk-like virus poses an additional problem with having a high probability of causing a secondary transmission as seen in a study by Heun et al (42). This study showed that pre-school aged children were particularly susceptible to secondary illness, double to that of adult illness at $70 \%$ and $31 \%$, respectively.

Both Norwalk-like virus and Snow Mountain Agent have been implicated in food borne outbreaks in school cafeterias. In a case control investigation of viral gastroenteritis outbreak on a university campus, Brockmann et al (43) through the use of a standardized questionnaire, sanitary inspection and laboratory investigation, determined that although laboratory findings were inconclusive to the causative agent, Norwalk-like viral agent was most probably transmitted via an ill food handler. In 1990, 787 dormitory residing students and 18 foodservice workers fit the case definition of illness after eating foods that were prepared in a central campus kitchen. In this case control study, one particular food item could not be implicated and is consistent with evidence that an ill food handler may have contaminated many foods. Although it was the policy of this university to relieve ill persons from food handling, it was determined that four of five symptomatic foodservice personnel continued working directly with food preparation, disregarding the existing protocol. Personal hygiene protocol was not followed.

Norwalk-like virus was also implicated as the probable cause of food borne illness outbreak in a Florida state county, following food eaten at a wedding rehearsal dinner and reception (44). Eighty-two people complained of gastrointestinal distress after 
consuming deviled eggs and roast beef. After an investigation by the Florida State Department of Health and Brevard County Health Department, it was found that the deli department, which had produced the roast beef, had unsanitary conditions, improper storage of foodservice equipment and utensils, mishandling of food products and poor hand washing stations. Although the investigators were unable to identify the food handler who may have been the carrier, symptoms of the outbreak support those seen with Norwalk-like virus, which is typically transmitted via the fecal-oral route due to unclean hands.

Guest et al (45) investigated an outbreak of gastroenteritis, which occurred in a co-educational high school in Brooklyn, New York. In a single cluster sample of 375 students, 129 , an attack rate of $34 \%$ met the criteria for Snow Mountain Agent (SMA) infection. It was discovered that three cafeteria workers had acute symptoms of gastroenteritis, however, continued to prepare and serve meals without gloves. When questioned about hand washing after restroom use, the staff claimed that they did, although disposable hand towels were unavailable for the staff. Storage temperatures for implicated foods were also kept at inappropriate temperatures, exacerbating the problem. The evidence of the outbreak implicates both personal hygiene of food handler and improper holding temperatures.

Although transmission of Hepatitis A virus, (HAV), to food is relatively low in terms of percentage ( $2 \%-3 \%)$, food contaminated with HAV usually arises from infected food handlers who practice poor personal hygiene while preparing food. In a study by Massoudi et al (6) assessment of a single food handler that is positive for HAV hygiene and illness symptoms is a recommended criterion for public notification. In 1994, a food 
handler employed with a catering company in Kentucky was solely responsible for preparing 38 of the 41 food items leading up to an outbreak. When questioned, the food handler reported following good hygiene practices after using the restroom and before preparing food, and he reported having no diarrhea during these days. It was found, however, that this food handler was responsible for preparing a number of high-risk foods (foods uncooked) like vegetable and fruit platters without the use of gloves. For three of the four events with high attack rates, eating at least one of several uncooked foods was associated with the illness. This study concluded that it was unclear how transmission occurred in this situation unless the food handler reported falsely concerning his personal hygiene practices. He may, in fact, have had diarrhea. It was also discovered that at two separate catering sites, there were no on-site sink or on-site kitchen.

Person-to-person shedding of Escherichia coli (0157:H7) has also been implicated in food borne illness and linked to poor personal hygiene of food handlers. Williams et al (7) have reported such an occurrence in a child day care. It appeared that outbreak was directly linked to poor hand washing of the children and staff before eating and serving. Proper hand washing technique and good personal hygiene practices are effective tools for the prevention of $E$. coli $(0157: \mathrm{H7})$ outbreak.

In foodservice, cross contamination of foods has been implicated in outbreaks. In a study by Rodrigue et al (8) and Shapiro et al (46) cross-contaminated roast beef and inadequate cooking and holding temperatures were the apparent causes of outbreak of Escherichia coli $(0157: \mathrm{H7})$ and Salmonella serotype Thompson, respectively. The roast beef was determined to be the likely source of the bacterium, and the slow cooking process may not have been adequate to thoroughly cook the internal portion of the beef. 
Cross-contamination of the Waldorf salad with that of the roast beef contaminant also contributed to the number of outbreak cases as seen by Rodrigue et al (8). Shapiro et al (46) found upon interview that the chefs admitted having lack of knowledge and were unaware of proper cooking and storage temperatures. From these studies, it is shown that food borne disease outbreaks have been directly linked to food handler, in terms of poor personal hygiene practices, temperature abuse and mishandling of foods during preparation.

\section{Food Safety Knowledge Gap}

Despite the coordinated food safety strategic planning effort, which includes consumer and foodservice education, there continues to be a major knowledge gap about food borne illness prevention and safe food handling among Americans. Survey findings from research conducted by Cornell University's Department of Food Sciences (9) found that $29 \%$ of Americans would allow cooked food to sit out on a counter until it reached room temperature. Only $54 \%$ of non-institutional food handlers knew to wash cutting boards with soap and water after cutting meat and before preparing raw vegetables.

Altekruse et al (10) using a national telephone survey, found that one third of those who prepared meals in kitchen facilities reported unsafe food hygiene practices such as handling food with unwashed hands or cross-contamination from cutting raw vegetables on the same cutting board as raw meats. This survey randomly selected 1,620 United States residents. The respondents were non-institutional food handlers, English speaking and $\geq 18$ years of age. These results raised concerns about the food-handling practices of Americans. 
In 1995 and 1996, the multi-state Behavioral Risk Factor Surveillance System (BRFSS) conducted by Altekruse et al (11) collected data from 19,356 completed questionnaires regarding food safety (handling, preparation and consumption) from adults from 8 U.S states: (1995: Colorado, Florida, Missouri, New York and Tennessee; 1996: Indiana, New Jersey and South Dakota). Results revealed risky food-handling and consumption practices. Overall, $19 \%$ of respondents reported not adequately washing hands or cutting boards after handling raw meat and/or poultry. Risky consumption behavior included eating undercooked hamburger and eggs ( $20 \%$ and $50 \%$, respectively), and eating raw oysters and drinking raw, unpasteurized milk ( $8 \%$ and $1 \%$, respectively). In this study, the behavioral surveillance was used to identify those behaviors most associated with risk of acquiring food borne illness and to develop targeted educational efforts, which may benefit consumers and food handlers.

To further examine food safety knowledge, Williamson et al (12) conducted a nationwide survey, which consisted of 49 questions formatted into a survey booklet to provide a design meant to be user friendly and appealing. The survey included questions in five major areas: demographics, food safety knowledge, home food preparation practices, food safety attitudes and perceptions and food safety information. Mailing lists of 2,005 randomly selected U.S. households were used in this study. To assess food safety knowledge, respondents were asked to correctly identify key food borne disease terms and concepts. Only $58 \%$ of the respondents knew that Staphylococcus spp. was associated with infected bodily cuts and $33 \%$ were unfamiliar with the term. In terms of food storage, $54 \%$ of the respondents said that they would store leftover stew in a deep pot, in which it was cooked. This clearly indicates that the respondents did not 
understand proper cooling methods. Thirty seven percent of the respondents said that they would only rinse a knife, which has just been used to cut raw meat before cutting vegetables. This indicated that these unsafe food-handling procedures would lead to cross contamination. In cross tabulating responses of food safety knowledge and food preparation practices, $23 \%$ respondents could identify the term Salmonella spp., however, they said that they would leave chicken on the counter in room temperature to defrost. Results of this survey revealed a lack of practical food safety procedures in the areas of temperature control, food-handling, and storage, cross contamination, and basic food borne disease terms and microbial causes.

There appears to be the assumption that proper food-handling is based on common sense, something learned as a child modeling home kitchen behaviors, however, this is not always found to be true. In a study by Beard et al (13) 50 consumers were interviewed to determine major causes of complaints about food, in terms of familiarity and expectations of the marketplace and consumer mishandling of food products. The researchers found a lack of knowledge within eight critical areas. Personal hygiene, keeping kitchen equipment sanitary, proper handling of foods en route from store to kitchen and proper storage and holding temperatures were highly lacking. It was found that out of 14 and 11 refrigerators and freezers, only 7 and 1, respectively, had thermometers. Temperature ranges for refrigerators and freezers were +32 degrees to +55 degrees Fahrenheit, and +5 degrees to +20 degrees Fahrenheit, respectively. Most homemakers were unaware of the importance of proper storing temperatures and the detrimental effects poor storage temperature can lead to. 
This concept was further supported by Maciorowski et al (14) who discovered that educational efforts would be effective in the areas of preparation, storage and thawing methods by poultry consumers. The researchers found that $57 \%, 79 \%$ and $55 \%$ of Hispanics, minors and uneducated respondents, respectively, stated that they would thaw poultry either on the counter, in the microwave or in a sink of water and not in a refrigerator. Consumer awareness may be accomplished through education. If the average consumer is practicing improper food-handling techniques at home, these may be the same persons hired for employment in foodservice. It should be a requirement of the hiring institution to provide training and continuing education especially to those persons hired for foodservice.

According to a study by Griffith et al (15) the type and amount of training is highly influential on the turnover rates seen in institutional foodservice. Training and education of employees is directly proportional to employee satisfaction and turnover rate. Unfortunately, high turnover is seen too often in institutional foodservice. This increases the chance of internal problems, which may manifest itself in poor foodhandling, which may ultimately lead to food borne outbreak. From these studies, it appears that there is a gap of food safety knowledge among American consumers and professionals. This is of concern because this lack of knowledge may be correlated to unsafe food-handling practices, which may increase the risk of food borne disease. Since there is a major gap of food safety knowledge among Americans, this gap may also exist among these Americans who are hired as food handlers in institutionalized foodservice. 


\section{Food Safety Knowledge, Attitude and Behavior of Foodservice Employees}

According to the CDC surveillance data for $1988-1992(2,31,39)$ food borne illness arising from foodservice establishments occurred because the food was:

1) mishandled, via food handler with poor personal hygiene which included poor or absent hand washing, 2) cross-contaminating foods with inherently contaminated food items such as raw meats and poultry and 3) temperature abuse consisting of improper cooling, inadequate cooking, reheating or thawing, and unsafe holding and storage temperatures. Unlike some types of disease, food borne diseases caused by microbial pathogens is preventable and the risk is reduced given the food handler receives effective food safety training. This training needs to be consistent and supported by management in order to be effective.

In an effort to determine a perspective on knowledge and task competency needed for safe food-handling practices, Linton et al (18) reviewed a study which included the formation of an advisory board consisting of food safety professionals, food scientists and psychometricians. The purpose of the advisory board was to determine food safety competencies, skills and knowledge needed by foodservice personnel. The advisory board, with collaboration from local and state regulatory agencies, foodservice and food retail industries, established a task-list survey. This task-list survey was then sent to randomly selected personnel of the Food and Drug Administration (FDA), Conference for Food Protection, Food Manager Certification Committee, Food Marketing Institute, Inflight food Service Association, International Association of Milk, Food and Environmental Sanitarians, National Automatic Merchandising Association and National Environmental Health Association. Demographics and five knowledge groups were 
investigated. These knowledge groups consisted of: food, cleaning, sanitizing and maintenance, facilities, food personnel, and regulatory issues. Tasks related to knowledge of food protection were all identified as most important knowledge aspects needed by foodservice personnel. Food protection tasks included safe food preparation, temperature control and the monitoring of personal hygiene and behaviors directly related to food safety practices. Deficiencies in these areas were the same reported by the Centers for Disease Control and Prevention as the main causes for food borne disease outbreak in foodservice $(1,2,31-34,39)$.

Emphasis should be placed on the prevention of food borne illness by ensuring safe food-handling by foodservice personnel through education and training about food safety principles. Identifying and understanding knowledge areas may be used to create effective food safety training programs necessary for the prevention of food borne disease outbreak. However, in surveys conducted by Bryan et al (47) and Wyatt et al (19) the researchers found foodservice employees to have a lack of information regarding food safety and general safe food-handling practices.

Walter et al (20) found that staff knowledge of safe food preparation of community-based homes is lacking, especially in the areas of storage and handling. A survey was given to a $10 \%$ probability sample of direct-care staff and dietitians in homes for people with developmental disabilities. In a self-administered questionnaire, the main outcome measures included food-handling knowledge, practices and attitudes. Respondents admitted to not always following safe food-handling practices, such as cutting vegetables on a board after cutting raw meat. This behavior has been linked to cross-contamination and may lead to food borne disease. Most respondents also reported 
having never attended a food safety-training program. This indicates the non-existence of a food-safety training program in this facility, and contributes to the knowledge gap found in foodservice employees.

In a comparative study by Manning (48), a significant lack of food safety knowledge of workers from temporary foodservice operations with that of institutional foodservice operations exists, especially in the areas of temperature control, cross contamination, storage and personal hygiene. This difference may be attributed to the institutional workers receiving on the job training and continuing education in order to meet accreditation standards of that institution. The questionnaire consisted of 14-Likert type attitude statements, multiple choice and true/false questions and eight demographic questions. Areas targeted in the questionnaire were those areas most frequently linked to the transmission of food borne illness outbreaks: cross contamination, cooling/reheating, and personal hygiene and temperature control. The questionnaire was given to 58 and 64 foodservice workers from the institutional and temporary foodservice operations, respectively. Using descriptive statistics and Student's t-test, statistically significant differences in demographics and food safety knowledge and attitude were identified for the two groups of foodservice workers in the areas of temperature control, cross contamination and cooling and reheating. Compared with temporary foodservice workers, more institutional workers had safe food-handling training on the job ( 26 versus 5). Attitudinal differences concerning personal hygiene and general food-handling existed between the two groups, where more institutional than temporary workers agreed they always need to wear a hair restraint Fewer institutional than temporary workers were comfortable with identifying spoiled food by smell or taste. These differences may 
be attributed to these institutional workers having on- the -job training and continuing education. This study shows a statistical difference in knowledge and attitude in those foodservice workers who do not receive food safety training, which may ultimately lead to unsafe food-handling practices and increased risk for food borne illness. It also showed the positive impact food safety training might have on knowledge, attitude and food safety behavior.

Active participation of food safety practice, even in institutions with established Hazard Analysis and Critical Control Point (HACCP) systems (49) is lacking perhaps in part due to lack of educational efforts to disseminate current information and updated protocol on food borne illness trends. This lack of knowledge present in the foodservice work force underlines either indifferent or negative attitude towards food safety practices on the part of the food handler. Educational programs specifically designed for foodhandlers employed at institutions should be frequent. Assessment of knowledge and attitude towards food safety should also take place in order to determine if this education might bring about positive behavioral change towards decreasing prevalence of food borne disease.

The HACCP system, developed by a facility-specific HACCP team, is based on the seven principles of Hazard Analysis and Critical Control Point (49): a) identify hazards, b) determine critical control points, $(\mathrm{CCP}), \mathrm{c}$ ) establish the critical limits that must be met at each $\mathrm{CCP}, \mathrm{d}$ ) establish procedures to monitor each $\mathrm{CCP}, \mathrm{e}$ ) establish corrective actions to be taken when there is a deviation, $f$ ) establish effective record keeping and g) establish procedures for verification that the HACCP system is working correctly. Teaching foodservice workers to critically think through food safety processes 
is an approach HACCP incorporates. However, even with a HACCP in place in a facility, in order for food safety to be deliberate on the part of the food handler, foodservice employees must be given the necessary and relevant training and education regarding safe food-handling practices.

\section{E. The Effectiveness of Food Safety Education and Training}

An approach to food safety education is that which promotes positive change with attitude, not just knowledge alone. Theories on attitude, knowledge and behavioral change concur that a positive behavior change will be more strongly connected with a person's willingness to make personal sacrifices or if they feel that they will be personally held responsible for their behavior.

Shaefer et al (30) found that foodservice workers were more motivated to practice safe food-handling behaviors when they believed that they could be personally harmed by not doing so. This approach was further shown in a study by Medeiros et al (21) in a safe food-handling curriculum designed for volunteer quantity cooks. The curriculum, entitled Safe Food Handling for Occasional Quantity Cooks, is modeled on the Hazard Analysis and Critical Control Point (HACCP) concept and stresses critical thinking in the identification of critical control points and the ramifications for not performing safe food handling procedures. This study presented two statewide in-services that were conducted on 71 foodservice participants (quantity and volunteer cooks, as well as camp foodservice directors and managers). The curricula consisted of a five-lesson outline that focused on behaviors, which would most likely prevent food borne illness: food purchase, storage, preparation, transporting or handling. In a pre-post-test design, knowledge of food safety 
increased $(P<0.05)$ as a result of attending the in-service. Results of the self-declared behavior checklist showed improvement after training when compared to pre-training. Travis (22) created a program designed to increase awareness of food safety and focused attention training staff employed in parks and recreation areas. This type of job had high turnover and employed college-age students who had basically no training in foodservice. The only foodservice professional was the cook. A slide series created for foodservice employees employed at Glacier National Park was reviewed by the U.S. Public Health and FDA officials, and focused on seven concepts of food safety: food temperatures, storage, dispensing, personal hygiene and handling practices, cleanup, utensil storage, and physical facilities. Although a pre-test was given prior to the training, no post-test was given to assess if there was an increase in knowledge. However, the training lead to improved sanitation scores and no food borne outbreaks were reported during the past three years at Glacier National Parks.

The effectiveness of food safety education and intervention programs on the improvement of knowledge and attitude scores in institutional foodservice has been studied. Rinke et al (23) found a significant increase in food safety knowledge of University resident hall food-handlers after receiving two food safety-training methods, live and taped instruction. This study included sixty employees who were randomly assigned to one of two treatment groups. One group received information via color 35 mm slides with instructor commentary and the other group received the same type of instruction, but with no instructor present. A pre-post-test was given. Results showed that there was a significantly higher gain in knowledge $(\mathrm{P}<0.01)$ achieved with the live instruction. Demographic differences in educational level showed that participants with a 
higher education ( $\geq 12$ grade) gained slightly more from the live instruction method, and those with less education ( $\leq 12$ grade) gained more from the taped instruction, however, the difference in gain scores was not significant.

In a safety education program developed by Fritz et al (24) targeted groups who served populations that if food borne illness was acquired, would potentially be a serious health threat. The target groups were a) congregate meal site managers, drivers and volunteers, b) family daycare providers', and c) family shelter staff. A variety of course material was developed, including visual aids, filmstrips, demonstrations and written fact sheets. The one-hour workshop concluded with group discussions of typical scenarios that could potentially lead to food borne outbreaks, the liabilities, and ramifications and how such outbreaks could be avoided. Pre-test questionnaires show that there was a high knowledge regarding the importance of proper food-handling, however, respondents often responded to thawing food at room temperature. Post-test showed fewer negative responses, where $64 \%$ of the participants reported at least one food-handling practice change after the workshop.

Soneff et al (25) looked at quality improvement of foodservice in communitybased Adult Care Facilities (ACF). With a pre-test/post-test design, forty-six ACF's were randomly assigned to one of three programs. One program consisted of receiving a oneday workshop plus a specifically designed manual for ACF's. The second program received the manual only and the third program received no intervention. Food safety scores significantly improved in pre- and post-audit, ranging from $33.4 \%-49.4 \%$ to $36.8 \%-56.2 \%$, respectively. The intervention that included the one-day workshop and manual resulted in a significant improvement in food safety scores as compared to the 
intervention that used only the manual without the workshop. This may suggest that improved learning results when several teaching methods are used to disseminate information.

Raval-Nelson et al (26) investigated the impact of food-safety training component of Philadelphia's food safety certification program. The researchers hypothesized that the educational component would cause food handlers to assimilate knowledge about hazards associated with improper food-handling and this would ultimately lead to a change in behaviors and practices that render food unsafe. The researchers found that more correct answers were received from certified than non-certified personnel, however, in certain question categories, the difference was insignificant. The results of the survey also indicated areas of food-safety training, which needed improvement. Correct cooking temperatures were one of these areas. This survey had practical implications, however, a measure of if the lessons taught were applied in a real foodservice setting needed further exploration.

Foodservice employee training has been recognized as an effective tool for maintaining quality in foodservice $(15,16,18)$. Quality foodservice would include welltrained food handlers who understand and practice the importance of food safety. Training also leads to better-motivated employees, lower turnover, job commitment and higher job satisfaction. All of this leads to maintaining a qualified labor pool to work in foodservice and lead to fewer outbreaks of food borne illness.

A study conducted by Cluskey et al (16) investigated information about training programs and the existence of potential labor problems in noncommercial foodservice operations. Results of the survey showed that the foodservice supervisor trains $81 \%-92 \%$ 
of non-supervisory employees, followed by dietitians and administrators at $68 \%$ and $88 \%$, respectively. Results also showed that sanitation training delivered the highest percentage at $96 \%$ with employee orientation coming up second at $94 \%$. However, $54 \%$ of the facilities surveyed responded that there were no specific techniques for reinforcing training on the job and $75 \%$ reported employee on the job performance to be evidence of employee knowledge before and after training. Although this study showed that $96 \%$ of the training was performed on sanitation, it is biased because the survey was mailed to directors and administrators and may not reflect the true percentage of non-supervisory employees that truly do get trained in this area. Reinforcement of job knowledge and performance evaluation was shown to be weak, at best, by this study, and this may contribute to behaviors not conducive to proper food-handling. Employee training plays an integral part to the success and quality of foodservice. The type and extent of training should be based on employee knowledge and attitude of job position, as well as properly targeted towards the population employed. All of these studies concur that there is an increased importance in having proper food safety education and training of personnel responsible for food-handling. Various training programs have shown a positive knowledge gain, as well as a shift in attitude, which has lead to behavioral change. This may ultimately lead to fewer outbreaks of food borne illness and the due diligence of food safety practices. 


\section{Summary}

We can determine from the current trends seen with food borne disease outbreaks, that the risk of getting ill from contaminated foods prepared by commercial food handlers poses a real threat in the United States. Research shows that outbreak of food borne disease is directly linked to lack of training and knowledge, poor attitude and low motivation of food handlers, and this may lead to practices that promote food borne illness. Currently, the literature shows that there is a lack of general food safety knowledge demonstrated in both the consumer and the foodservice professional. This lack of knowledge has lead to practices that have caused food borne outbreaks. Active observation of food safety practice and behavior is strongly correlated with increased knowledge and improved attitude towards food safety. Thorough and formal training, retraining, consistent emphasis on the necessity of safe food-handling practices and an appropriate internal control and management support are all major elements for the prevention of food borne disease outbreak. 


\section{Chapter III}

\section{Purpose of the Study}

Food borne illness continues to be a rising problem in the United States, contributing to high mortality and morbidity, as well as costing billions of dollars in healthcare and surveillance (1). Particularly susceptible to complications and death caused by ingestion of contaminated foods are those population groups that may be immuno-compromised such as those with wasting diseases like cancer and AIDS. According to the Centers for Disease Control and Prevention (CDC), the state of Florida currently ranks third in the total number of persons with HIV (50). Other population groups susceptible to complications from food borne disease include the elderly, infants, children, pregnant women, and those of low socioeconomic status with limited resources and access to healthcare (3).

Pathogenic microorganisms have been found to be the greatest cause for food borne illness $(1,2,4,31,32,36,38,39)$. Transmission of these pathogens has been directly linked to poor food-handling practices of food handlers (4-8). Poor food-handling has been positively correlated to a knowledge gap in proper food safety practices, as well as poor and inconsistent training of foodservice personnel (9-16). A current challenge faced by dietitians and foodservice managers is the trend of hiring unskilled labor, high employee turnover, lack of management support and effective training material, and/or non-adherence to regulations such as those set forth by Section 103 (d) of the Americans with Disabilities Act (37), the Federal Register (38) and the Food Code (51).

Current studies show that food safety education increases the level of knowledge, and improves foodservice employee attitudes towards the practice of food safety 
(18,21-26). Studies have also shown that this may translate to positive behavioral changes towards the due diligence of food safety (27-29). Food safety training when incorporated into on-the-job-training has also been shown to improve motivation and self-esteem of employee, as well as increase productivity, decrease turnover rate and increase the quality of foodservice $(15,16)$. Thorough understanding of outbreak trends, training of personnel, re-training and enforcement of protocol and policy, compliance standards, collaboration with educators, regulators and the science community, and effective training programs are all crucial components for the prevention of food borne disease outbreak.

In reference to these issues, and given that school aged children are particularly susceptible to illness and mortality from food borne pathogens coupled with the increasing number of HIV positive children reported in Miami-Dade County $(3,50,52)$ and who may consume foods prepared by institutionalized public school foodservice, it becomes ever more crucial that safe food-handling practices exist within these institutions. Research has shown that the majority of foods borne illness outbreaks were caused by foods prepared in institutionalized foodservice by food handlers $(1,4,6-$ $8,13,43-46$ ). Currently, it is not a Florida State mandate for foodservice workers of public schools to have food handler certification or formal food safety education, as it is with foodservice workers employed by privately owned public restaurants (53). In public school foodservice, implementation of food safety training and on-the-job reinforcement is the responsibility of the school foodservice manager. Thus, it was the purpose of this study to investigate the effect of food safety education and training of foodservice employees from inner city public schools in Miami, Florida. Food safety knowledge, 
attitude and behavior of foodservice workers in an experimental group was assessed before and after a 3-hour food safety training and compared with a control group that received no food safety training. We hypothesized that those foodservice workers who received food safety training would have improved their knowledge, attitudes about and behavior toward food safety issues compared to those who did not receive food safety training.

\section{A. Objectives of the Study}

The major objective of this study was to assess the need for food safety training for foodservice employees of inner city public schools.

The specific objectives were as follows:

1. To determine food safety knowledge of inner city school foodservice employees.

2. To determine attitudes and behavior of inner city school foodservice employees toward food safety.

3. To investigate the effectiveness of a 3-hour food safety in-service training on the knowledge, attitude and behavior of inner city school foodservice employees.

4. To determine the relationship between knowledge, attitude and behavior toward food safety practices.

\section{B. Research Hypotheses Tested}

Hypothesis 1: Foodservice employees who received a food safety in-service training would have increased knowledge of food safety compared to those who did not. 
Hypothesis 2: There would be an improvement in attitude towards the importance of food safety by foodservice employees who received a food safety in-service training compared to those who did not.

Hypothesis 3: There would be an improvement in behaviors toward food safety practices of foodservice employees who received a food safety in-service training compared to those who did not.

\section{Research Approval}

The Institutional Review Board (IRB) of Florida International University approved this research study as an exempt status on December 17,2000 , exempt number 121700-01 (Appendix A). Miami-Dade County Public School Board (MDCPS) also gave approval to conduct this research study on October 17, 2000, approval number 704 (Appendix B). Prior to entering the participating school's foodservice facility, telephone calls were performed and letters were sent to each of the schools' Principals to inform them of the objectives of the study (Appendix C). 


\section{Chapter IV}

\section{Methodology}

\section{A. Subjects and Incentive to Participate in the Study}

Four inner city public schools from Miami-Dade County, Florida were chosen for this study. The four schools were located approximately within a 5-mile radius from each other. All foodservice workers employed at the participating schools spoke and understood English and were demographically similar. The participating schools were: Charles Drew Middle School, Liberty City Elementary School, Lillie C. Evans Elementary School and Poinciana Park Elementary School. The convenience sample of schools were chosen by the Director of Operations of Regions I, II and III of the Department of Food and Nutrition of Miami-Dade County Public Schools. Thirty-four cafeteria foodservice workers, employed at the participating schools, participated in this study. A foodservice worker was defined as any person directly involved in handling, preparing, cooking, serving, storing and/or cleanup and was eligible to participate. The foodservice managers $(n=4)$ were also eligible to participate. Any foodservice worker actively participating in any other food safety training was excluded from the study.

An oral explanation of the objectives of this study was given and all participants were verbally made aware that involvement was voluntary and information collected would be kept confidential. A participant's voluntary response to taking the pre- and post-test and attendance to the in-service (if applicable for the group) was an indication that they agreed to participate. If at any time during the study the participant wished to discontinue, they were free to do so without any form of repercussion. Due to the innocuous nature on the rights and welfare of human subjects, coupled with the 
applicability of exempt status of section IV.A. 2a and b of the Institutional Review Board (IRB) of Florida International University guidelines, requesting a signed consent was waived based on justification found in section C. $3 \mathrm{a}$ and $\mathrm{d}$ of these guidelines. There were no risks or discomforts involved in the participation of this study.

Participation in this study was voluntary and those who chose to take part received monetary compensation by Miami-Dade County Public Schools (MDCPS) for time spent as per their employment status with MDCPS. As an extra incentive, breakfast was offered at the intervention site to all those in the experimental group who took part in the food safety training. Pencils with the emblem, Fight Bac Partnership for Food Safety Education and a brochure entitled, Fight Bac Four Simple Steps to Food Safety (54) (Appendix D) were given to all those who participated in the study as a token of appreciation. The brochure gave tips on how to: 1) keep hands and surfaces clean, 2) avoid cross-contamination, 3) cook to proper temperatures, and 4) chill and refrigerate food. The brochure also included an internal temperature reference chart on various food items and information on how to acquire more food safety information. The four foodservice managers were given calibrated food thermometers approved by the National Sanitation Foundation (NSF International) (55) to use during a portion of this study. They were welcomed to keep the thermometers at the end of the study.

\section{B. Data Collection Modules}

\section{Pre-test and Post-test Questionnaire}

In a pre-test/post-test/control quasi-experimental type design, Charles Drew Middle School was randomly selected from the four participating schools as the control 
group and the three elementary schools, Liberty City, Lillie C. Evans and Poinciana Park, were grouped as the experimental group. The latter received one, 3-hour food safety education in-service training and the control group received no food safety training.

Upon developing the pre-test/post-test questionnaire designed for this study, it was given to foodservice workers of an elementary school that were not part of the participating schools in the study. Nine foodservice employees, including one foodservice manager, and who were ethnically matched to the participants of the research study subjects, participated by answering questions regarding demographics, general food safety knowledge and attitude. Cronbach alpha scores for knowledge and attitude were 0.7 and 0.5 , respectively. Questions regarding behavior were subsequently added to the questionnaire and Cronbach alpha for these questions scored at 0.3 .

The pre-test/post-test questionnaire (Appendix E), which contained 10 demographic questions, 30 multiple choice and true/false type food safety knowledge questions, 20 five-point Likert type attitude and 12 five-point Likert type behavior questions was then used in the research study. The questionnaire was given to each participant of both groups, control and experimental, approximately one week before and one week after the scheduled food safety training took place. Schedules and times appropriate to give the participants the questionnaire were set up between the researcher and each of the foodservice managers. They were notified via telephone call, e-mail communication, and written schedule (Appendix F) as to the particular dates of pretesting, foodservice facility inspection, food safety in-service training (if applicable), and post-testing. 
On the scheduled pre- and post-test days, questionnaires were given to subjects at the end of the work shift as to not interfere with the foodservice operation. Prior to handing out the questionnaire to the participants, the researcher explained the objectives of the study (Appendix $G$ ) and informed them that taking the pre- or post-test was voluntary and confidential. The participants were given approximately 45 minutes to answer the questionnaire containing questions on demographics, food safety knowledge, attitude and behavior. Collaboration on answers to the questionnaire was prohibited. Upon completion of the questionnaire, they were collected and checked for completeness by the researcher and placed in an envelope. The questionnaires were kept confidential and locked in a file cabinet until analysis of the data was performed.

\section{Foodservice Facility Inspection}

Pre- and post foodservice facility inspections were performed by the researcher at each of the participating schools on the same day as the scheduled pre-test and post-test questionnaire was given. The purpose of the inspection was to determine if a 3-hour food safety training translated into improved food-handling behaviors. The report form used for this inspection was a checklist created by the researcher and based on a modified version of the Foodservice Establishment Inspection Report published by the Department of Health Education and Welfare (56) (Appendix H). Areas that were inspected included Food, Food Protection, Personnel, Food Equipment and Utensils, Toilet and Hand Washing Facilities, Refuse Disposal and Inspection of the Walls, Floors, Ceiling, Lighting and Ventilation. The researcher subjectively answered either "yes", "no" or "not applicable" to questions pertaining to the various areas that were inspected. The 
facility inspection took approximately one hour to complete and was performed prior to and during either the breakfast or lunch time period during which there is the greatest activity of foodservice. The pre- and post facility inspections of all participating schools were performed at approximately similar times for consistency.

\section{Time and Temperature Evaluation}

On the days scheduled for the foodservice facility to receive the pre- and post-test questionnaire and foodservice facility inspection, the researcher also showed the foodservice managers how to perform time and temperature evaluations of food. The purpose of these recordings were to determine if foods were cooked, held and served at the proper temperatures. Length of time between when the food was cooked and served was also determined. A bimetallic thermometer, approved by the National Sanitation Foundation (NSF International) (55) for taking temperatures of the food was given to each of the foodservice managers to perform this aspect of the study. The foodservice managers were welcomed to keep the thermometer at the end of the study as a token of appreciation. The researcher calibrated the thermometers according to the manufacturer's directions prior to the start of pre-and post-test temperature recordings. On a form created for this portion of the study (Appendix I), the foodservice managers were asked to record temperatures of food upon completion of cooking or preparing (if the item was a cold dish), and holding and serving temperatures of menu items being served for five consecutive days. Cooking endpoint times and serving times were also recorded on these forms. This was performed approximately one week before and one week after the food safety training. The forms were pre-printed and dated by the 
researcher and included written instructions on how to use them. A binder, labeled with the name of the facility, and the pre-printed, dated forms were given to the foodservice managers for organization and storage of the forms. Follow-up calls were made to each of the foodservice managers after the first complete day of recording the time and temperatures of the foods to clarify any questions that might have arisen. These binders, which held the completed forms, were collected and checked for completeness by the researcher approximately one week after completion from each of the facilities. The researcher noted any of the five consecutive days that did not have time or temperatures recorded.

Foodservice managers are also required by Miami-Dade County Public Schools to record the temperature and the time the temperature was taken for all of the facility's refrigerators and freezers. The forms that were used for this aspect of the study were the current forms in place and used by the facility according to Miami-Dade County Public School policy (Appendix J). The researcher collected copies of these forms from each of the participating facilities approximately one week before and one week after the food safety training. The purpose of this aspect of the study was to monitor the equipment temperatures, as well as the actual record keeping.

\section{Food Safety Training}

A 3-hour food safety in-service training was held approximately one week after the last school performed the pre-test questionnaire. The food safety training occurred on a "Teacher Planning Day" when schools were closed to students. The foodservice employees were off duty on this day. The foodservice employees of the experimental 
group convened in the cafeteria of Liberty City Elementary School at 8:00 am. Breakfast was offered to all in attendance and supplied by Miami-Dade County Public Schools.

Following the breakfast and an explanation of the food safety training objectives by the researcher, a series of 6 videotapes on food safety issues was shown. The first video, entitled Introduction to Food Borne Illness (57), covered an overview of causes of food borne disease. Various pathogenic organisms and the roles they play in food borne illness were discussed. The next five videotapes shown were part of the Food Protection Video Series (58) created by the University of Florida in collaboration with the National Restaurant Association. This series of videotapes were used in this study because the information is disseminated in a way applicable to foodservice personnel. Video 1 in the series covered Food Safety and Personal Hygiene. Video 2 in the series covered Receiving, Storing and Record Keeping. Video 3 of the series covered Thawing Cooking, Cooling and Holding Food. Video 4 of the series covered Serving, and video 5 of the series covered Cleaning and Sanitizing. Following the viewing of each videotape, a discussion, question/answer and active participation session were held before viewing the next videotape. Since proper hand washing techniques were stressed in the videotapes, the researcher gave a live demonstration. Active participation of each foodservice employee to demonstrate proper hand washing technique concluded the in-service. A commercially sold "germ powder" (59) was placed on their hands before and after proper hand washing to further demonstrate the importance of proper hand washing. When a hand held ultraviolet light was passed over their hands, areas that were not properly washed fluoresced a bluish-glow. Although this was not a quantitative measure of bacteria, this aspect of the in-service gave a visually demonstrative example of proper 
hand washing. The participants were clearly amazed at seeing the results of proper hand washing techniques.

Upon completion of the in-service, participants were asked to complete a program evaluation (Appendix K) and sign an attendance sheet (Appendix L) before exiting. The purpose of the evaluation form was to determine strengths and weaknesses of the training and to receive feedback by the participants.

Approximately two weeks after the in-service, a post-test containing identical questions as the pre-test but in a differing order, was given to both groups as previously described. At this time, a post inspection of the foodservice facility and new food time/temperature evaluation forms were placed in the binders given to the foodservice managers to use as previously described. The researcher also recalibrated the bimetallic thermometers at this time. The binders, which held the completed forms, were collected and checked for completeness by the researcher approximately one week after completion from each of the facilities. The researcher noted any of the five consecutive days that did not have time or temperatures recorded. This concluded the data collection portion of the study.

\section{Statistical Analysis}

Statistical Package for the Social Sciences for Windows 10.0 (SPSS 10.0) was used for data analysis. Descriptive statistics were used for characteristics of the participants, pre-post facility inspections and the time and temperature data, as well as the food safety in-service training evaluation. Paired t-test on pre-post-test results within the group was performed. Independent samples t-test between the control and experimental 
pre-test knowledge, attitude and behavior scores was also performed. McNemar's Chisquare was used to analyze attitude and behavioral changes. 


\section{Chapter V}

\section{Results}

A total of 34 participants were eligible for this study. Two participants voluntarily withdrew prior to the conclusion of the study allowing for a total of 32 participants to complete this study. Charles Drew Middle School was randomly selected as the control group, and ten foodservice employees participated as the control group $(n=10)$. Liberty City, Lillie C. Evans and Poinciana Park elementary schools, were grouped as the experimental group and twenty-two foodservice employees participated as the experimental group $(\mathrm{n}=22)$. The latter received one, 3-hour food safety education inservice training and the control group received no food safety training.

Descriptive characteristics of the participants are shown in Table 1. There were no significant differences between the socio-demographic characteristics by group. All the participants were residents of Miami-Dade County. The majority of the participants were female, with one male participant in each of the groups. Most participants were younger than 50 years of age. The mean age of the participants was $43 \pm 12.4$ years old. The youngest and eldest participant was 19 and 63 years old, respectively. All participants, except one were Black, non- Hispanic. The mean years of education of the participants were $11 \pm 1.3$ years. All participants, except one had some high school education, and $56 \%$ of these showed completion of high school. Only two participants had post-secondary education. Of years of foodservice employment, greater than $50 \%$ of participants had less than 10 years experience. While $44 \%$ of the participants had greater than ten years of foodservice experience, the greatest number of years working in foodservice for a single participant in the control and intervention group was 35 and 30 
years, respectively. Salary ranges of the participants indicated that the majority of employees made less than $\$ 9,999$ per year. According to the poverty guidelines published by the Department of Health and Human Services (60), this would place the participants at the poverty level set for families with one or greater members. 


\section{Table 1}

Socio-demographic characteristics of foodservice employees of inner city public schools from Miami-Dade County, Florida, who participated in a food safety training study $(\mathrm{N}=32)$

\begin{tabular}{|c|c|c|}
\hline Characteristic & $\mathbf{N}$ & $\%$ \\
\hline \multicolumn{3}{|l|}{ Residence (County) } \\
\hline Miami-Dade & 32 & 100 \\
\hline \multicolumn{3}{|l|}{ Gender } \\
\hline Male & 2 & 6 \\
\hline Female & 30 & 94 \\
\hline \multicolumn{3}{|l|}{ Age (Years) } \\
\hline $18-49$ & 22 & 69 \\
\hline $50+$ & 10 & 31 \\
\hline \multicolumn{3}{|l|}{ Race } \\
\hline Black, Not Hispanic & 31 & 97 \\
\hline Hispanic & 1 & 3 \\
\hline \multicolumn{3}{|l|}{ Education (Years) } \\
\hline $7-11$ & 12 & 38 \\
\hline $12-15$ & 20 & 62 \\
\hline \multicolumn{3}{|c|}{ Employment in Foodservice (Years) } \\
\hline$<10$ & 18 & 56 \\
\hline$>10$ & 14 & 44 \\
\hline \multicolumn{3}{|c|}{ Salary (Dollars Per Year) } \\
\hline$<9,999$ & 16 & 50 \\
\hline $10,000-40,000$ & 11 & 34 \\
\hline Unanswered & 5 & 16 \\
\hline
\end{tabular}


Results shown in Table 2 indicate that prior to this study, the majority of participants had previous food safety training. This concurs with the requirement of foodservice employment with Miami-Dade County Public Schools. These results include two participants that initially began the study, however, voluntarily withdrew before the conclusion. The mean amount of time reported since the last food safety training was 4 years and 8 months \pm 7 years and 3 months. The greatest and least number of years reported by participant since the last food safety training was thirty years and two months ago, respectively. The significance of this question was to determine if and how long ago the participants had food safety training. Results indicate inconsistencies of food safety training. Results also imply that regular and continual food safety training does not occur. 


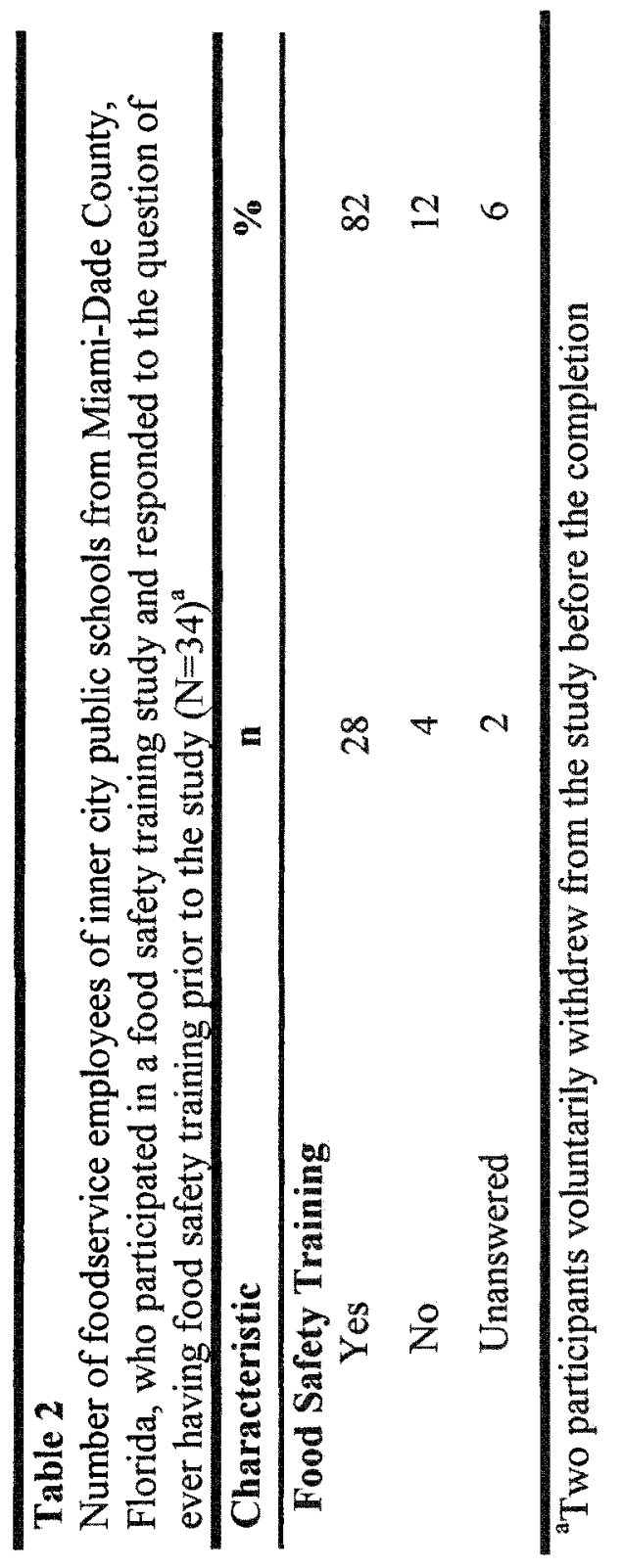


The pre-test and post-test scores describe food safety knowledge before and after a 3-hour food safety in-service training, respectively. Differences between mean scores on the pre- and post-test are interpreted as representing a gain in food safety knowledge. The mean knowledge scores and change in food safety knowledge by group before and after a 3-hour food safety in-service training is represented in Table 3. The mean pre-test scores for the control and experimental group were $57.7 \pm 14.7$ and $53.0 \pm 14.8$, respectively. Results of an independent samples t-test indicate that the pre-test average scores were not significantly different from each other $(\mathrm{P}<0.42)$ when equal variances were assumed. This showed that the two groups were not significantly different in terms of food safety knowledge before the 3-hour food safety in-service training. The mean pre-test and post-test scores for the control group were $57.7 \pm 14.7$ and $60.0 \pm 12.3$, respectively. The mean pre-test and post-test scores for the experimental group were $53.0 \pm 14.8$ and $65.3 \pm 14.0$, respectively. The mean differences between pre- and post-test scores for the control and experimental group were $2.3 \pm 11.2$ and $12.3 \pm 14$, respectively. This indicates that food safety training significantly increased food safety knowledge $(\mathrm{P}<0.001)$ in the experimental group. The increase of knowledge is reflected in questions concerning general food safety, causes of and prevention of food borne illness. The control group, which did not receive any food safety training, did not show a significant increase in knowledge. 


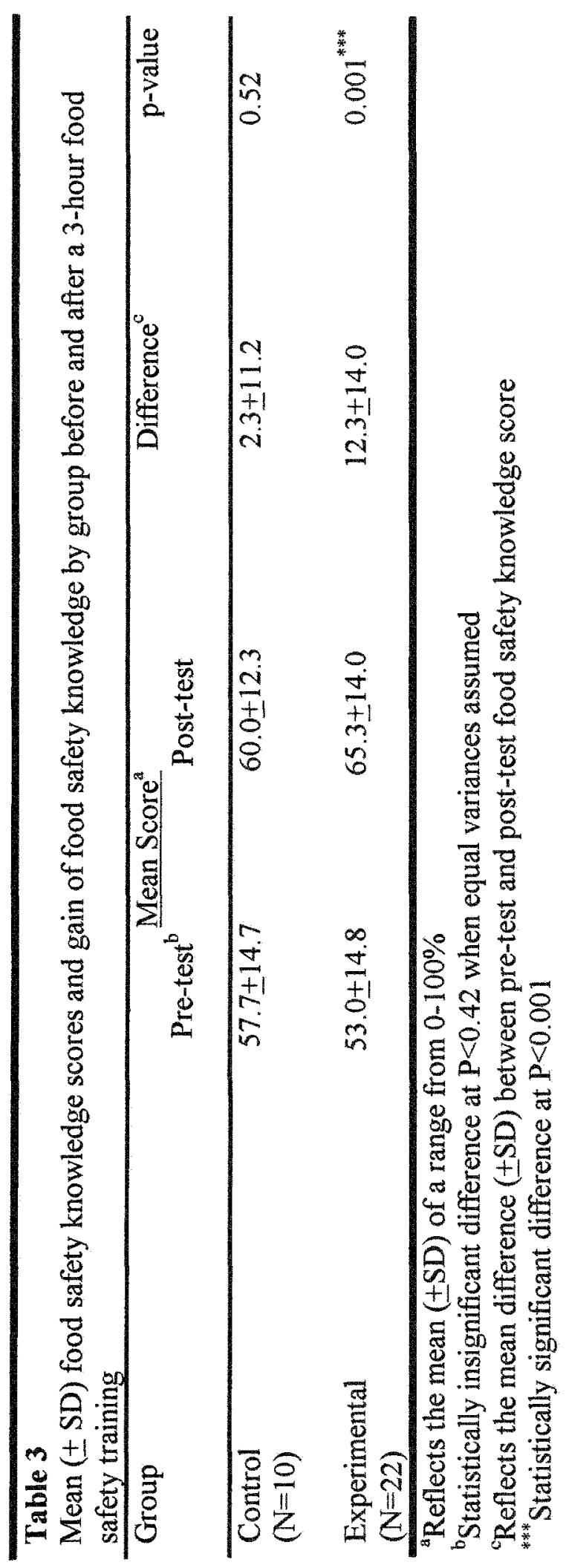


A five-point Likert Scale was used to determine both attitude and behavior scores.

A score of one indicates that the participant strongly agrees with the question or statement, and a score of five indicates that the participant strongly disagrees. Pre-test and post-test scores describe food safety attitude before and after a 3-hour food safety inservice training, respectively. Differences between mean scores on the pre- and post-test are interpreted as representing a positive change in attitude towards food safety issues.

Table 4 shows the mean attitude scores and change of outlook towards food safety concepts by groups before and after a 3-hour food safety in-service training. The mean pre-test scores for the control and experimental groups were $4.0 \pm 0.5$ and $4.12 \pm 0.5$, respectively. Results of an independent samples t-test indicate that the pre-test average scores were not significantly different from each other $(\mathrm{P}<0.57)$ when equal variances were assumed. This showed that the two groups were not significantly different in terms of food safety attitude before the 3-hour food safety training. The mean pre-test and posttest scores for the control group were $4.0 \pm 0.5$ and $4.38 \pm 0.3$, respectively. The mean pretest and post-test scores for the experimental group were $4.12 \pm 0.5$ and $4.04 \pm 0.5$, respectively. The mean differences between pre- and post-test scores for the control and experimental group were $0.38 \pm 0.3$ and $-0.08 \pm 0.3$, respectively. The negative difference shown with the experimental group indicates a slight decline in attitude and outlook towards concepts of food safety. Although the control group showed a marginally significant increase in attitude $\left({ }^{+} \mathrm{P}<0.10\right)$, the results show that the 3 -hour food safety training did not significantly influence a positive feeling towards food safety conception. 


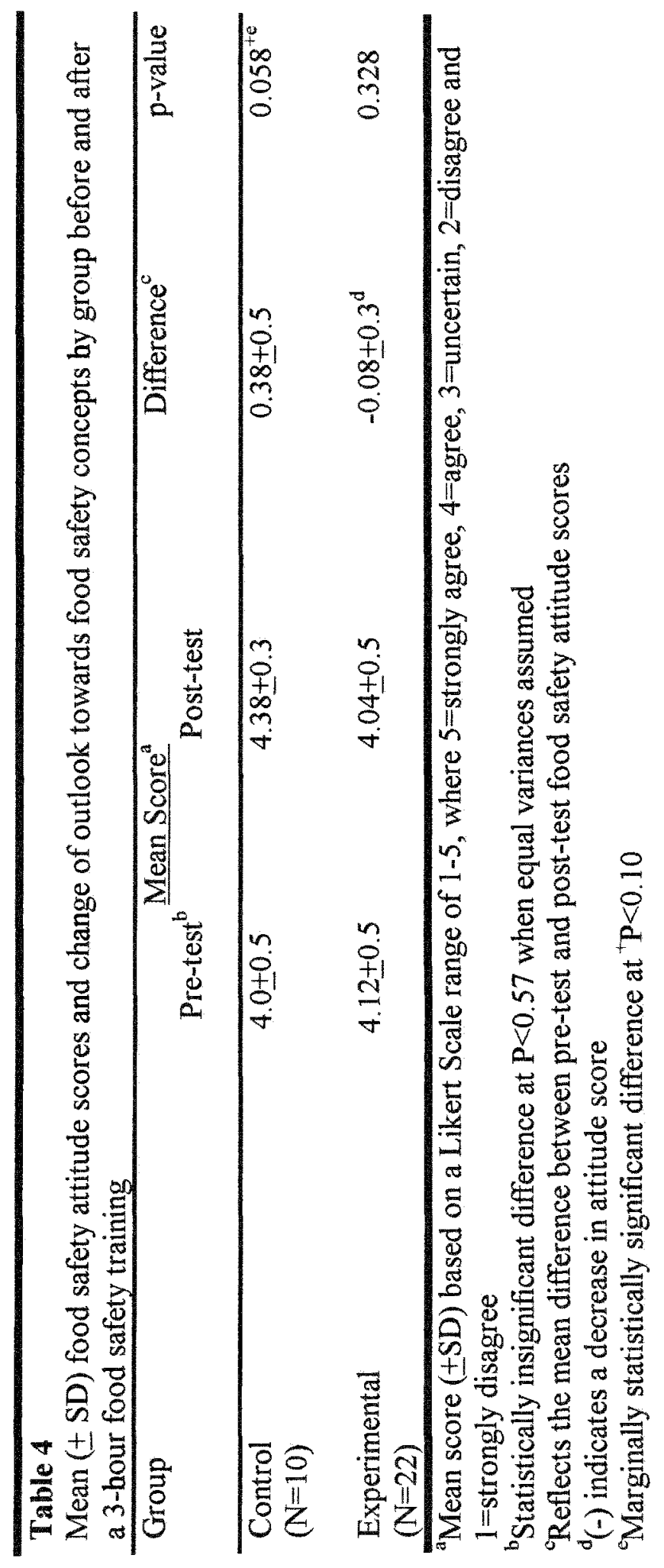


The mean behavior scores and change in food safety practice by group before and after a 3-hour food safety in-service training is represented in Table 5. Differences between mean scores on the pre- and post-test are interpreted as representing a positive change in food safety practice. The mean pre-test scores for the control and experimental group were $4.39 \pm 0.4$ and $4.44 \pm 0.4$, respectively. Results of an independent samples ttest indicate that the pre-test average scores were not significantly different from each other $(\mathrm{P}<0.69)$ when equal variances were assumed. This showed that the two groups were not significantly different in terms of food safety behavior before the 3-hour food safety in-service training. The mean pre-test and post-test scores for the control group were $4.39 \pm 0.4$ and $4.30 \pm 0.3$, respectively. The mean pre-test and post-test scores for experimental group were $4.44 \pm 0.4$ and $4.38 \pm 0.4$, respectively. Both groups showed a slight decline in post-test score after the 3 -hour food safety in-service training. The mean differences between pre- and post-test scores for the control and experimental group were $-0.09 \pm 0.5$ and $-0.06 \pm 0.3$, respectively. The negative difference shown with the control and experimental groups indicate the practice of behaviors conducive to food safety standards worsened after the 3-hour food safety training, although these results were not statistically significant. 


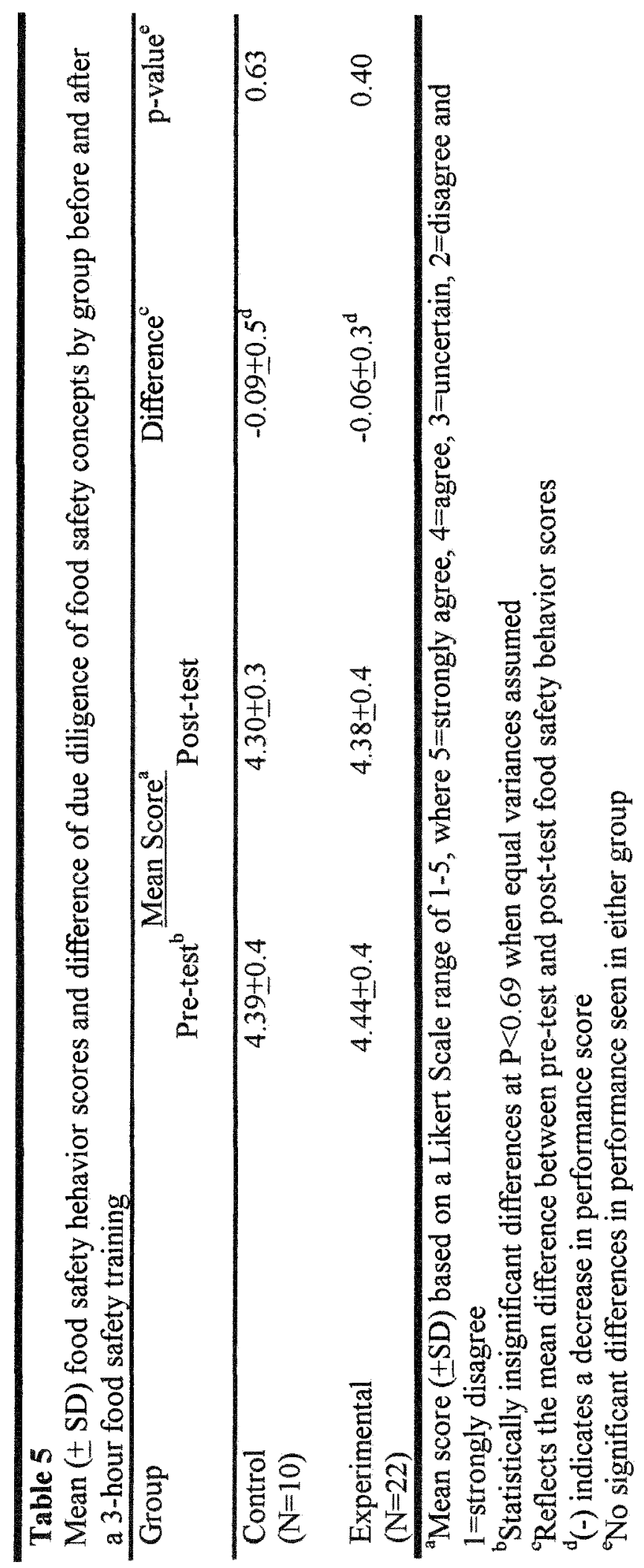


Results of the facility inspection for the experimental schools are shown in Tables

6 and 7. Represented in these two tables are differences seen in various areas of the experimental school's foodservice facility, demonstrated after a 3-hour food safety inservice training. The number of schools in the experimental group $(\mathrm{N}=3)$ that show a positive improvement within these foodservice areas is shown in Table 6. Increase in number of schools indicates schools whose foodservice facility revealed enhanced food safety practices in areas of food protection, personal hygiene and maintenance of dishwashing equipment. Results indicated the areas that showed the greatest improvement were in food protection, personal hygiene of the food-handler and maintenance of dishwashing equipment. 


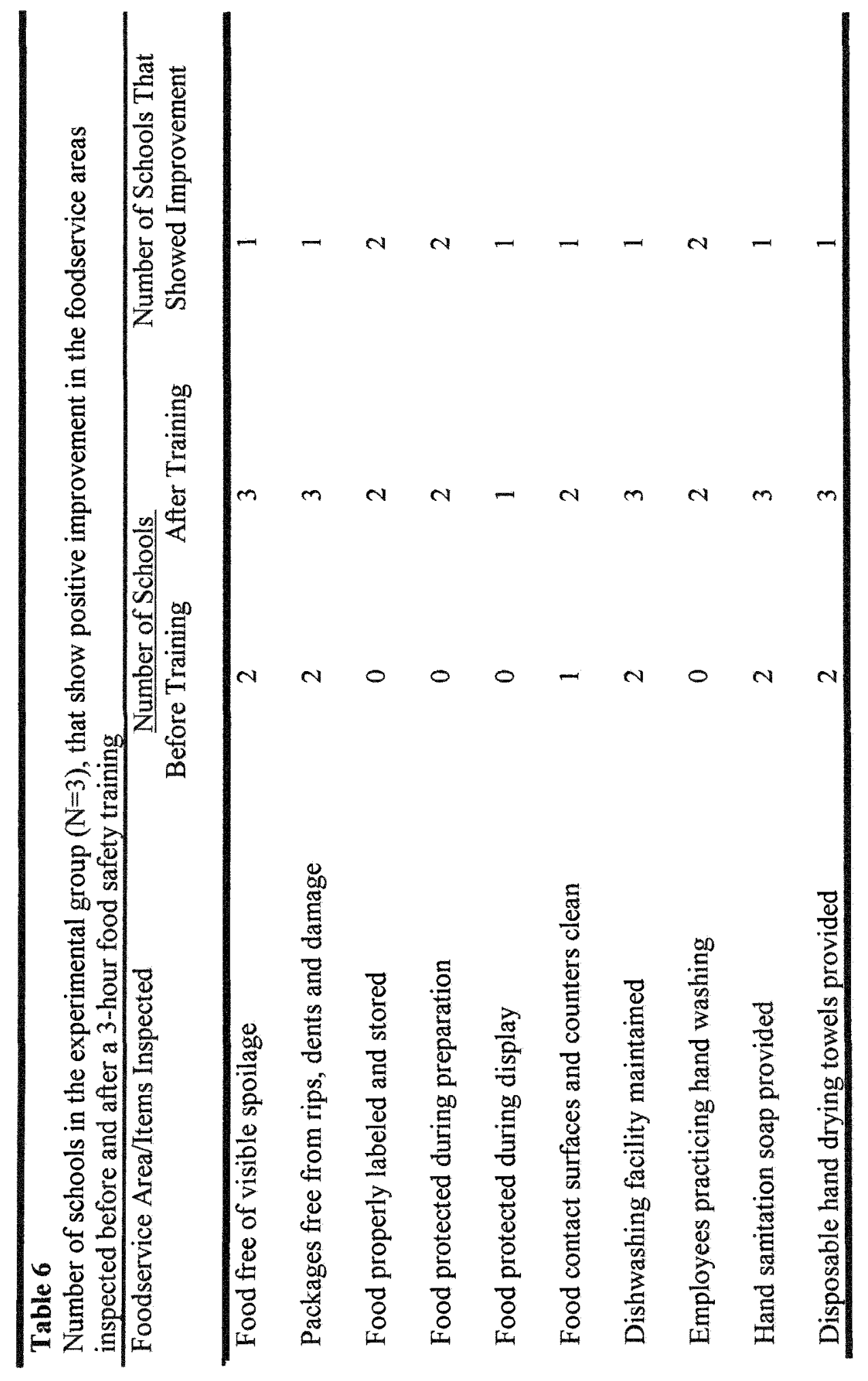


The number of schools in the experimental group $(\mathrm{N}=3)$ that did not show improvement or demonstrated a decline of inspected areas of the foodservice facility before and after a 3-hour food safety in-service training is shown in Table 7. All three schools demonstrated no improvements in foodservice areas that deal directly with freezer, refrigerator and storage temperatures, use of thermometers and food protection during storage. Observations made of the proper use of disposable gloves indicated a decline in schools that used gloves appropriately, weakening from 3 schools down to only 2 schools. Results also indicated that all 3 schools failed to have clean walls and ceiling surfaces after the food safety training. Chipping paint and water stains on the walls and ceilings were noted. 


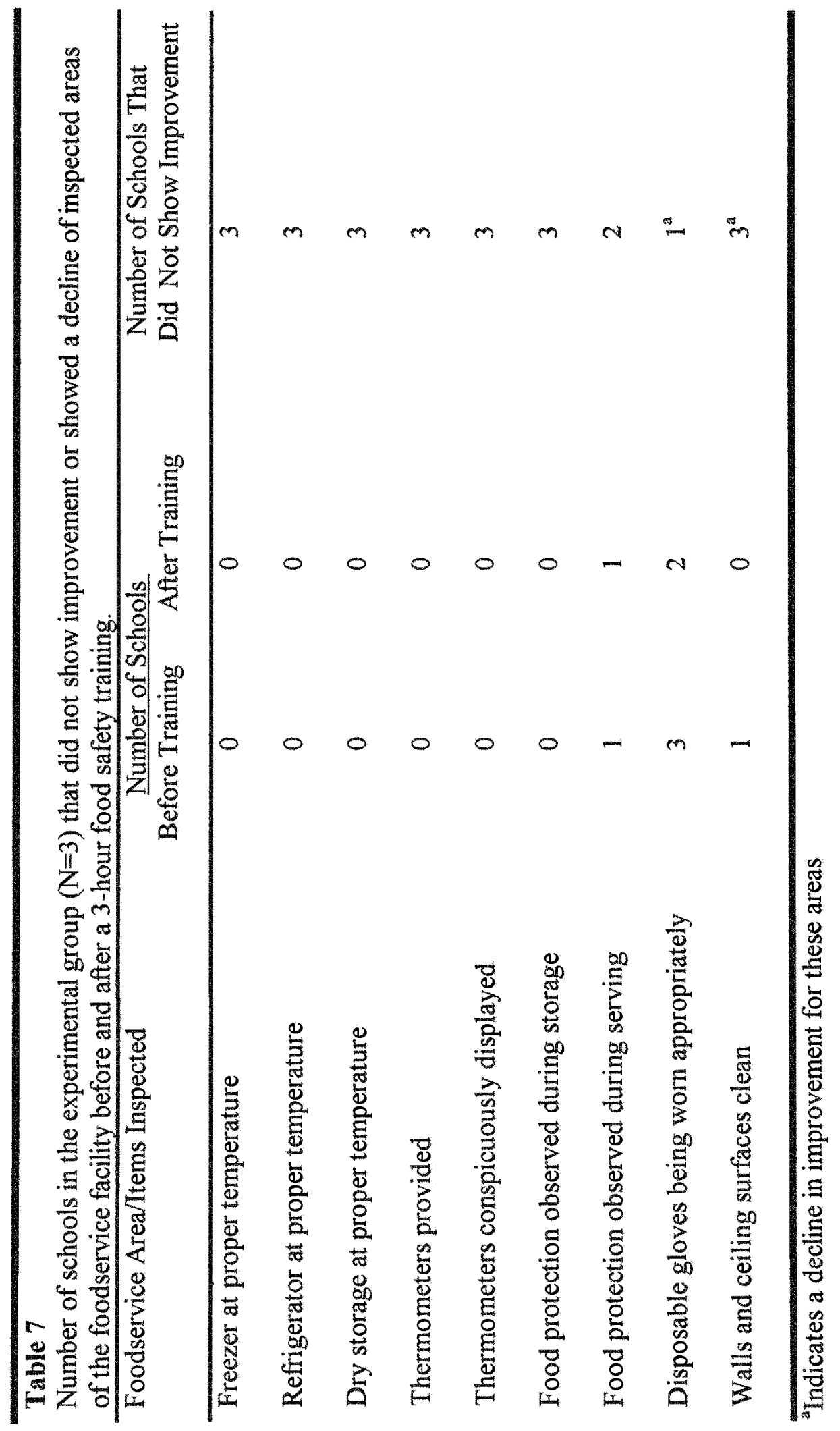


Participants were asked to evaluate the food safety in-service training at its conclusion. Sixteen participants completed the evaluation. The purpose of the evaluation was to determine the overall success of the training in terms of meeting the objectives and to allow for feedback by the subjects. The results in Table 8 clearly showed an interest and appreciation of food safety education among foodservice employees. Results of the evaluation also showed that the design and delivery of the training was adequate to meet objectives. Most importantly, the evaluation also indicated that the participants felt that that the training taught them the necessary skills needed to practice safe food handling techniques. 


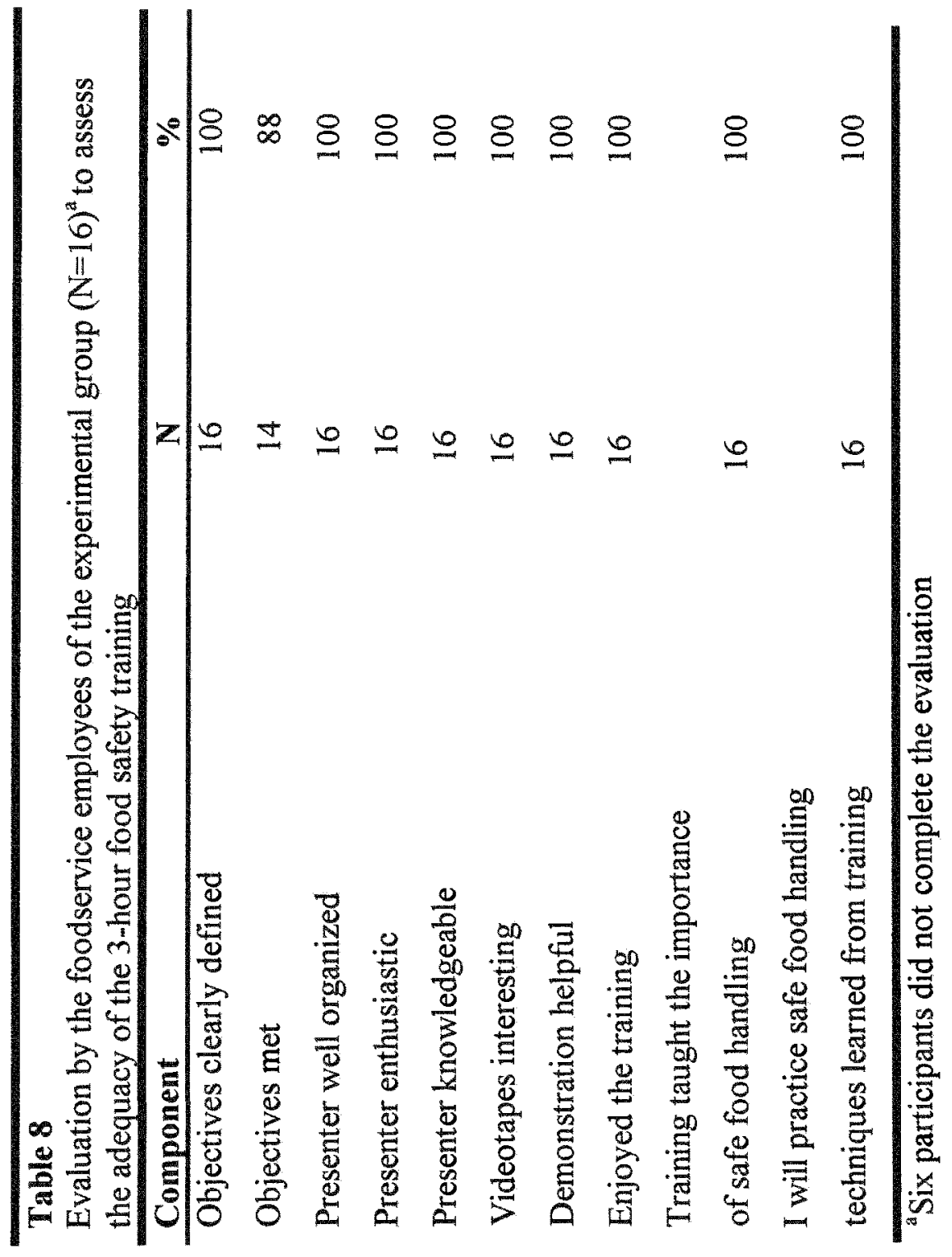




\section{Chapter VI}

\section{Discussion and Limitations}

In institutionalized foodservice operation, such as that offered in the public school system, it is the responsibility of all food handlers to ensure that the food is safe for consumption. The foodservice employees need to be certain that the food they serve to the public is prepared, stored and served in a way that meets the food safety standards. However, in order to expect this kind of commitment from these employees, they must first be able to recognize food-handling errors, which may have devastating consequences. This type of knowledge may come from formal education or on the job training. Research shows that those who completed a college course that included food safety information had significantly higher knowledge about the subject (27).

Foodservice employers and employees should be aware that food borne disease is not caused by a single event, but arises from collective causes. However, despite raised awareness on the dangers and causes of unsafe food, adherence and performance to food safety standards continues to be a challenge to the foodservice industry.

Food borne pathogens are particularly hazardous to at-risk populations such as pregnant women, the elderly, infants, children and those with immuno-compromised health such as those with AIDS and cancer (3). Food safety behaviors are paramount in the health and well being of this population. Infants and children, who are already at risk to food borne illness due to their age, if stricken with immune-compromising diseases such as HIV and AIDS, they are at an even greater risk for disease and death if unsafe food is consumed. This is something that invariably must be considered in view of current HIV and AIDS trends in the United States. According to the Centers for Disease 
Control and Prevention, Florida ranks third highest in the number of cumulative AIDS cases as of June 2001, with 83,005 cases reported. Florida also ranks second in the reported pediatric cases (50). According to the Miami-Dade County (MDC) Department of Health Surveillance Report of persons with AIDS, a total of 22,852 cases were reported. Four hundred sixty-seven of these were pediatrics. The remaining 22,385 reported cases include both adolescents and adults who have reported AIDS and HIV positive (52). This is a significant fact to consider when keeping foods offered in the public schools safe. These children and adolescents may be consuming foods prepared for them by institutionalized foodservice facilities such as the public school cafeterias, and may add to dilemma of the already at-risk population group.

Raising awareness and knowledge of food-handling errors is the first step in reducing outbreaks of food borne illness and can best be accomplished through food safety training. We hypothesized that foodservice employees who received a food safety training course would have increased knowledge about food safety compared to those who did not. This hypothesis was accepted. This study showed that food safety knowledge improved in the areas of general food safety, recognition of common microbial pathogens found on foods often served in public school foodservice, and on how to prevent and reduce microbial growth through proper food-handling practices, maintaining adequate internal temperature and cooking endpoint times, and personal hygiene. These findings concur with current research that food safety training increases knowledge and can be used to identify areas where knowledge is lacking in order to create training programs that may focus on these areas of weakness $(14,19-25,49)$. 
Research showed that having a change in knowledge level about food safety might also influence an employee's attitude and outlook towards it (21-26). Research also showed that having a positive predisposition, towards a situation might bring about skills and behaviors conducive to safe food-handling $(21-29,49)$. In keeping with the research, this study also hypothesized that food safety training would positively influence the personal outlooks and attitudes of the foodservice employees towards issues such as good personal hygiene and general food safety practice, as well as improve due diligence of safe food handling techniques. These hypotheses, however, were not proven. Findings from this study did not demonstrate that food safety training positively influences outlook towards or practice of safe food-handling. It was interesting to find that in this study, after food safety training was given, and as food safety knowledge increased, both attitude and behavior decreased as seen in the experimental group. Although a small change was noted in attitude in the control group of this study, the result was insignificant. Due diligence of food safety technique in both groups also appeared to worsen, and behaviors that could be conducive to food borne outbreak still occurred.

Further support for these notions of unimproved attitudes and behaviors were also exemplified by both groups in this study in terms of poor compliance to correctly and adequately record cooking endpoint temperatures, cooking completion and holding times, and also the temperatures at which the foods were served. Of the four foodservice managers assigned to this task of the study, only two managers, both from schools of the experimental group, attempted to complete the recordings. Results of these recordings, 
however, showed improper serving temperatures of many hot and cold items. Many food items were held for periods of time within the danger zone of 40-140 degrees Fahrenheit. Multiplication of microbial growth occurs most rapidly at this temperature, and may lead to spoilage of food, as well as increase the risk for food borne disease outbreak. No difference in behaviors to improve these temperature and time abuses were noticed in the recordings conducted post food safety training. During the facility inspections, it was also discovered that time and temperature abuse occurred and behaviors did not improve post food safety training. These findings are congruent with studies that show time and temperature abuse to be common in foodservice establishments, as well as the primary cause for food borne outbreaks $(1,2,4,39-41)$.

Inadequate refrigerator, freezer and storage temperatures were also noted for both groups of schools in this study. This appeared to be caused by incorrect recording of temperatures by the foodservice employee and/or inadequate functioning of the equipment. The facility inspection also noted that there were many missing or broken thermometers. Internal temperatures of food stored in the refrigerators and freezers were improper, possibly indicating malfunctioning of the refrigerators and freezers. Although the temperatures of the refrigerators and freezers have wide fluctuations due to time of day and how often the doors are opened, it was noted in this study, that temperatures taken later in the day appeared to be identical to that taken first thing in the morning. Oftentimes this was noted in equipment that did not have adequately working or missing temperature thermometers.

This study did, however, show marginal improvements in foodservice facilities of schools with regards to behaviors shown to protect foods during preparation and display, 
as well as improved personal hygiene of the foodservice employees. Studies have shown that poor personal hygiene of the food handler has been directly linked to food borne disease outbreaks (1,4-8,43-46). Prudence in hand washing technique and good hygienic practices may reduce the risk of food borne disease outbreak (4-8), and this was noted to improve in most of the foodservice employees of this study after food safety training. Coupled with the gain of food safety knowledge seen in this study, the challenge is to translate this knowledge into due diligence.

The seemingly negative attitudes and worsening or unchanged behaviors seen in some of this study's results may have been influenced by several factors. In terms of mean differences measured, using a 5-point Likert Scale may have caused a "ceiling effect" by skewing the participant's responses towards either the higher or lower end of the scale. Offering only a 5-point response scale did not provide a range of responses amongst the participants. In addition, the majority of responses appeared to be consistently similar on both the pre-test and post-test. In either case, there is no way to determine if the participant understood the degree or importance of the question asked. It was difficult to discern whether there was a change that was brought about by food safety training. Having only 20 and 12 attitude and behavior questions, respectively, may also not be sufficient to determine a change in these variables.

The size of the population for both the control and experimental group may have also negatively influenced the results. The population size was very small for the control and experimental group, $n=10$ and $n=22$, respectively. This would translate to having a weak statistical power, thus determination of differences in attitude and behavior would be difficult to detect. 
The geographically close radius of the schools to each other may further explain inconsistent results seen between the control and experimental group. This may have caused a high incidence of communication among the foodservice workers between schools. In addition, since this study took place in the inner city of Miami, Florida, it is not uncommon to have family members working for the schools within the same vicinity. This may have also caused a bias and socially, a type of competitive action among foodservice workers of the schools involved in the study.

Finally, one, 3-hour food safety in-service training may not have been sufficient to influence both attitude and behavior in foodservice employees. Results of this study showed that some of the participants had been in foodservice for many years without having consistent food safety training. Concepts taught in the food safety training inservice may have been new to them, and not enough reinforcement could have been given within the short time span of the training. Research shows that attitudes and behaviors are developed over a long period of time throughout the course of one's lifetime and based on individual characteristics, beliefs, attributes and environmental influences (61). It is unlikely that single, sporadic food safety training in-service would be enough to change these attributes. Research also shows that having increased knowledge about food safety concepts may not necessarily translate into behavioral change (28). A study by Clayton et al (29) showed that despite receiving food safety training, $63 \%$ of self-reported behaviors of food-handler responses admitted to not practicing food safety behavior concepts taught to them in training.

In addition to determining the level of knowledge, attitude and behavior of foodservice employees of inner city public schools and the effectiveness of 3-hour food 
safety in-service training, the major objective of this study was to assess the need for food safety training. This study did show that the training was sufficient to increase knowledge about food safety concepts, however not enough to influence an attitude or behavioral change. Small positive behavioral changes were noted in facility inspections, however, consistency in upholding these practices was not determined. Results of this study have shown that food safety training is necessary and critical in public school cafeteria foodservice. However, a true translation of knowledge to action may have to be further investigated. 


\section{Chapter VII}

\section{Conclusions and Recommendations}

Despite raised awareness and collaborative efforts by federal, private and institutional agencies to reduce the incidence of food borne disease outbreaks, the number of occurrence that is still being reported is staggering (1). Food borne disease outbreak is caused by a multitude of determinants and entities. Pathogenic microorganisms, each with its own life requirements, rate of growth and mode of destruction exists in today's food supply. The food that we consume is not sterile, and if certain environmental and external factors exist which allows multiplication of these microorganisms to occur, this may lead to illness if the food is consumed. Poor food-handling techniques, which includes cross-contamination, increased length of time between cooking and serving food, temperature abuse, and poor personal hygiene of the food handler are leading causes of food borne outbreak today $(1,4-8,34-36,42-45)$. Changes in societal lifestyles which contributes to more frequent use of institutionalized foodservice is the current trend, and may promote food borne illness by focusing more on convenience rather than food safety (17).

With multi-factorial causes for food borne disease outbreaks, strategies to decrease food-handling errors and increase food safety awareness, especially in those responsible for serving food for public consumption, need also be multi-dimensional. There still exists a tremendous gap between food safety knowledge and food safety practice in both consumer and those responsible for food protection $(1,9-14,20,49)$. This study attempted to determine the knowledge, attitude and behavior among foodservice participants of food safety training. Although the results gathered by this study are not 
conclusive, they are consistent with previous research that shows food safety training as the key factor in increasing knowledge $(10,13,14,16,18,19,20-26)$. However, knowledge, attitude and behavior are three different dimensions, and bringing about an increase in knowledge might not necessarily bring about an attitude and behavioral change, as seen in this study.

Research has shown that influencing behavioral change is a difficult challenge $(30,61)$. However, effective and consistent food safety education and training of foodservice employees is the first step in assuring that food safety concepts are at least introduced. On-the-job training has also been shown to increase work ethic, job satisfaction and decrease employee turnover rates $(15,16)$. In this study, it was shown that food safety training was neither consistent or a priority, however, results of the inservice training evaluation showed that there is tremendous interest, appreciation and effort to learn food safety concepts. Those in charge of institutionalized foodservice should make food safety training just as much a priority as it is to produce the day's menu in a timely manner.

Another approach to influencing change in food safety behaviors may lie in the philosophy and delivery of the training program. Research shows that those education programs that focus on the Health Belief Model to change food-handling behaviors is most often successful if the participants themselves feels a perceived threat of food borne illness or its repercussions $(30,62)$. It has also been shown interventions that use the Structural Model System, or an individual-level focus approach such as individual counseling, or small group approach may also influence knowledge, attitude, and 
behavioral change (61). Successful food safety programs may need to focus on sociobehavioral beliefs in order to change health behaviors.

In keeping with the Healthy Guidelines for Americans 2000 and 2010, food safety is included for health promotion and disease prevention (63). Those responsible for serving food to the public have the continued onus of ensuring it is safe to consume. Especially when feeding our children in public school foodservice, and considering all the Federal guidelines public schools must adhere to in terms of serving nutritious menus, we must not forget that foods must be safe to eat as well as nutritious.

Coupled with continuous employee training, institution of Hazard Analysis and Critical Control Point, (HACCP) system should be in place to reduce risk of food borne disease. Hazard Analysis and Critical Control Point has been shown to improve foodservice facility inspections and decrease food borne disease outbreaks $(47,49)$. This type of risk management process allows for process control and should be included in the fight against food borne disease outbreak. Steps for implementation are outlined in the United States Department of Agriculture (USDA) in collaboration with the Food and Drug Administration (FDA) Food Code (51). However, implementation requires management support, understanding of the concepts, consistent training and continual follow up. HACCP is not the cure-all. Although HACCP principles (discussed in the literature review section of this study) provide guidelines for use, implementation and adherence is dependent upon those directly involved with food protection. Lack of management support or mismanagement may cause a breakdown in HACCP effectiveness. 
In keeping with HACCP principles, all foodservice establishments should consider mandatory food sanitation certification for all those responsible for food protection. According to Florida State Statute 509.039 (53) all foodservice managers must hold food sanitation certification given by an approved program. However, public school foodservice is exempt of this mandate. Although many public foodservice facility managers may hold certification, many of the employees responsible for the actual handson preparation, display and serving of food are not certified. Sanitation certification should be considered because it may offer a structural education most needed in foodhandling services. Certification also allows responsibility of food safety to fall on those most directly responsible for feeding the consumers.

Strategies that promote safe food need to be collaborative and continual. Federal regulations and surveillance systems identifying common pathogens and their origins are already in place $(2,31-36,39,40)$. Since the foodservice institution is the last place food is processed and handled before it is served to the public, continued surveillance should occur. One way to accomplish this in a foodservice establishment may be to adopt a risk analysis framework of process control $(47,63)$. This may be considered as an expansion of the HACCP ideology. Risk analysis, which is comprised of three parts, risk assessment, management and communication, is a type of structured process for determining risks associated with any type of hazard found in food. In risk assessment, the foodservice institution may identify foods that have high risk to contamination and then chose not to serve those foods. Currently, the Federal government is performing research to identify risk assessment of certain foods in order to establish universal guidelines and quantitative data (64). Once the risk is assessed for a food type or process, 
risk management outlines what actions need to be taken in order to minimize contamination and reduce food borne disease. This may include taking that particular food item off the menu. Finally, risk communication is the key to the success of the entire process. This should include consistent food safety education based on current scientific knowledge.

Food safety training programs should meet the needs of the persons being trained in terms of educational level, socio-demographic characteristics, as well as sociobehavioral attributes. In accordance to the American Dietetic Association's position on food and water safety, food safety training programs need to be developed as a collaborative effort between the scientific, government, public and private institution (65). Benchmarking, and creating partnerships with other foodservice facilities would also provide a collaborative effort to improve food safety.

In conclusion, this study showed that there is a need for consistent and continual food safety training. Programs implemented should not only increase knowledge about food safety issues, but also affect the psycho-social domain which may influence behavioral change. Education and consistent and mandatory training, coupled with risk analysis, HACCP and food-handler sanitation certification may help to reduce food borne disease and increase food safety awareness and due diligence. 


\section{REFERENCES}

1. Partnership For Food Safety Education. Elevating the importance of safe food handling among consumers. Available at: http://www.fightbac. org/tbi/elevate. htm. Accessed January 01, 2000.

2. Olsen Sonja J, MacKinnon Linda C, Goulding Joy S, Bean Nancy H, Slutsker Laurence. Surveillance for food borne-disease outbreaks-United States, 1993-1997. MMWR Morbid Mortal Wkly Rep. 2000;49:1-53.

3. Gerba CP, Rose JB, Haas CN. Sensitive populations: who is at the greatest risk? Int $J$ Food Microbiol. 1996;30(1-2):113-123.

4. Levine WC, Smart JF, Archer DL, Bean NH, Tauxe RV. Foodborne disease outbreaks in nursing homes, 1975 through 1987. JAMA. 1991;266(15):2105-2109.

5. Olson Rebecca K, Eidson Millicent, Sewell Mack C. Staphylococcal food poisoning from a fundraiser. Env Health. 1997;7-11.

6. Massoudi Mehran S, Bell Beth, Paredes Valentine, Insko Judy, Evans Karen, Shapiro Craig N. An outbreak of hepatitis A associated with an infected food-handler. Pub Health Reports. 1999;114:157-164.

7. Williams Lloyd D, Hamilton Patrick, Wilson Bruce W, Estock Mark D. An outbreak of Escherichia coli 0157:H7 involving long term shedding and person-to-person transmission in a child care. Env Health. 1997;9-14.

8. Rodrigue Daniel C, Mast Eric E, Greene Katherine D, Davis Jeffrey P, Hutchinson Margaret A, Wells Joy G, Barrett Timothy J, Griffin Patricia M. A university outbreak of Escherichia coli $0157: \mathrm{H} 7$ infections associated with roast beef and an unusually benign clinical course. J Infect Dis. 1995;172:1122-1125.

9. Partnership For Food Safety Education. Taking the pulse of the general public: major knowledge gap about foodborne illness prevention. Available at: http://www fightbac.org/fbi/gap htm. Accessed January 26, 2000.

10. Alketruse SF, Street DA, Fein SB, Levy AS. Consumer knowledge of foodborne microbial hazards and food-handling practices. J Food Prot. 1996;59(3):287-294.

11. Alketruse SF, Yang S, Timbo BB, Angulo FJ. A multi-state survey of consumer food-handling and food-consumption practices. Am J Prev Med. 1999;16(3):216-221.

12. Williamson DM, Gravani RB, Lawless HT. Correlating food safety knowledge with home food-preparation practices. Food Tech. 1992;94-100. 
13. Beard TD III. HACCP and the home: the need for consumer education. Food Tech. 1991;123-124.

14. Maciorowski KG, Ricke SC, Birkhold SG. Consumer poultry meat handling and safety education in three Texas cities. Poult Sci. 1999;78(6):833-840.

15. Griffith Ruth $T$, Moore Aimee N, Krause Gary F. Effect on turnover of training foodservice employees. $J$ Am Diet Assoc. 1974;65:43-45.

16. Cluskey Mary, Messersmith Ann M. Status of training programs and perceived labor problems in four types of noncommercial foodservice operations. J Am Diet Assoc. 1991;91:1239-1242.

17. Collins Janet E. Impact of changing consumer lifestyles on the emergence/reemergence of food borne pathogens. Emerg Infect Dis. 1997;3(4):471-479.

18. Linton RH, McSwane $\mathrm{DZ}$, Woodley $\mathrm{CD}$. A comparison of perspectives about the critical areas of knowledge for safe food handling in food establishments. Env Health. 1998;8-15.

19. Wyatt CJ. Concerns, experiences, attitudes and practices of food market managers regarding sanitation and safe food handling procedures. J Food Prot. 1979;42:555-560.

20. Walter A, Cohen NL, Swicker RC. Food safety training needs exist for staff and consumers in a variety of community-based homes for people with developmental disabilities. J Am Diet Assoc. 1997;97:619-625.

21. Medeiros LC, George RT, Bruns K, Chandler C, Crusey S, Fittro J, Hill M, Jess M, Miller C, Reid J, Welker $\mathrm{E}$. The safe food handling for occasional quantity cooks curriculum. J Nutr Educ. 1996;28(1):39-43.

22. Travis HR. Training for seasonal foodservice operations. J Env Health. 1986;48(5):265-267.

23. Rinke WJ, Brown NE, McKinley MM. Two methods for instructing personnel about foodservice sanitation. J Am Diet Assoc. 1975;67:364-367.

24. Fritz BR, Cohen NL. A food safety education program targeting food handlers in high risk settings. $J$ Nutr Educ. 1989;21:284F-284G.

25. Soneff R, McGeachy F, Davidson K, McCargar L, Therien G. Effectiveness of two training methods to improve the quality of foodservice in small facilities for adult care. $J$ Am Diet Assoc. 1994;94:869-873. 
26. Raval-Nelson Palak, Smith Paulette $M$. Food safety certification and its impacts. Env Health. 1999;9-12.

27. Unklesbay N, Sneed J, Toma R. College students' attitudes, practices and knowledge of food safety. J Food Prot. 1998;61(9):1175-80.

28. Angelillo IF, Viggiani NM, Rizzo L, Bianco A. Food handlers and foodborne diseases: knowledge, attitudes and reported behavior in Italy. J Food Prot. 2000;63(3):381-385.

29. Clayton DA, Griffith CJ, Price P, Peters AC. Food handlers' beliefs and selfreported practices. Int $J$ Environ Health Res. 2002;12(1):25-39.

30. Shafer RB, Shafer E, Bultena GL, Hoiberg EO. Food safety: an application of the health belief model. J Nutr Educ. 1993;25:17-24.

31. Special report on selected notifiable disease in the United States, 1994.

MMWR Morbid Mortal Wkly Rep. 1994;43(53):19-22.

32. CDC Preliminary FoodNet Data on the incidence of food borne illnesses: selected sites, United States, 1999. MMWR Morbid Mortal Wkly Rep. 2000;49(10):201-211.

33. Eddy Christopher, Ingram Timothy, Leever Jeffrey. The Norwalk Virus: a guidance template for local environmental health professionals. J Env Health. 2000; 8-13.

34. CDC Surveillance Summaries preliminary FoodNet data on the incidence of food borne illnesses: selected sites, United States, 2001. MMWR Morbid Mortal Wkly Rep. 2002;51(15):325-329.

35. Bryan Frank L. Impact of food borne disease and methods of evaluating control programs. JEnv Health. 1978;40(60):315-323.

36. CDC Surveillance Summaries foodborne diseases active surveillance network, 1996. MMWR Morbid Mortal Wkly Rep. 1997;46:258-261.

37. The Americans with Disabilities Act of 1990, 42 USC 12101.

38. Notices. Federal Register. August 16, 1991;56:40897-40898.

39. Bean NH, Griffin PM, Goulding JS, Ivey CB. Foodborne disease outbreaks, 5-year summary, 1983-1987. MMWR Morbid Mortal Wkly Rep. 1990;39:15-57.

40. US Department of Agriculture/Food Safety Inspection Service. Food safety research agenda. Available at: http://www. fsis usda.gov/OPHS/fsragend.htm. Accessed January 26, 2000. 
41. Centers for Disease Control and Prevention/US Department of Health and Human Services. Addressing emerging infectious disease threats to health; a prevention strategy for the United States. 1994.

42. Heun Elizabeth M, Vogt Richard, Hudson Paul J, Parren Steve, Gary William. Risk factors for secondary transmission in households after a common-source outbreak of Norwalk gastroenteritis. Am J Epidem. 1987;126(6):1181-1186.

43. Brockmann Robert A, Lenaway Dennis D, Humphrey Charles D. Norwalk-like viral gastroenteritis: a large outbreak on a university campus. J Env Health. 1995;57(10):19-22.

44. Bodager Dean, Jackow George R. Outbreak of gastrointestinal illness associated with food served at a wedding reception. Fl J Env Health. 2001; 172:8-11.

45. Guest Charles, Spitalny Kenneth C, Madore H Paul, Pray Katherine, Dolin Raphael, Herrmann John E, Blacklow Neil R. Food borne snow mountain agent gastroenteritis in school cafeteria. Pediatrics. 1987;79(4):559-563.

46. Shapiro R, Ackers ML, Lance S, Rabbani M, Schaefer L, Daugherty J, Thelen C, Swerdlow D. Salmonella Thompson associated with improper handling of roast beef at a restaurant in Sioux Falls, South Dakota. J Food Prot. 1999;62(2):118-122.

47. Bryan FL. Risk assessment of foodservice establishments in communities. J Food Prot. 1982;45:93-100.

48. Manning CK. Food safety knowledge and attitudes of workers from institutional and temporary foodservice operations. J Am Diet Assoc. 1994;94(8):895-897.

49. Bryan Frank L. Hazard analysis critical control point approach: epidemiologic rationale and application to foodservice operations. JEnv Health. 1981;44(1):7-14.

50. Centers for Disease Control and Prevention-Division of HIV/AIDS PreventionBasic Statistics. Available at: http://www.cdc.gov/hiv/stats.htm. Accessed May 16, 2002.

51. Foods and Drug Administration. FDA Food Code 2001. Available at: http://www cfsan.fda. gov/ dms/foodcode.html. Accessed May 9, 2002.

52. The Miami-Dade County Health Department. Office of HIV/AIDS services. Available at: http://www. dadehealth.org/hivstd/std hiv shtml. Accessed May 16, 2002.

53. The Florida Legislature. The 2001 Florida Statutes. Available at: http://www.reg.state.fl.us/Statutes/1 ... SEC039.htm. Accessed June 23, 2002. 
54. Partnership For Food Safety Education. "Fight Bac". Available at: http://www. fightbac org html. Accessed July 18,2000.

55. National Sanitation Foundation, International. NSF, International. Available at: http://www nsf.org/Standards. Accessed May 16, 2002.

56. US Department of Health, Education and Welfare, Food and Drug Administration. Food Service Sanitation Manuel. U.S. Government Printing Office, Washington, DC 7475 .

57. Food and Nutrition. Introduction to food borne illness. Creative Educational Video. Lubbock, TX. Tape \#675.

58. University of Florida. The food protection video series. Order Number SFV785.

59. Health Education Company. WRS Group, Waco, TX.

60. US Department of Health and Human Services. The 2002 HHS poverty guidelines. Available at: http://www.aspe.os.dhhs.gov/povety/02poverty htm. Accessed May 16, 2002.

61. Cohen Deborah A, Scribner Richard A, Farley Thomas A. A structural model of health behavior: a pragmatic approach to explain and influence health behaviors at the population level. Prev Med. 2000;30:146-154.

62. Hanson, Jennifer A, Benedict Jamie A. Use of the health belief model to examine older adults' food-handling behaviors. J Nutr Educ Behav. 2002;34:S25-S30.

63. Woteki Catherine E, Facinoli Sandra L, Schor Danielle. Keeping food safe to eat: healthful food must be safe as well as nutritious. $J$ Nutr. 2001;131:502S-509S.

64. U.S. Department of Agriculture/Food Safety and Inspection Service. Risk assessment of $E$. coli $0157: \mathrm{H} 7$ in ground beef. Available at:

http://www.fsis.usda.gov/OPHS/ecolrisk/home.htm. Accessed May 28, 2002.

65. Position of the American Dietetic Association: food and water safety. J Am Diet Assoc. 1997;97:184-189. 
APPENDICES 
Appendix A

Florida International University

IRB Approval 


\title{
(9) \\ Florida International University
}

Office of the Director

\section{MEMORANDUM}

\author{
To: \\ Lilian Craggs \\ $\mathrm{CC}:$ \\ Dr. Zisca Dixon \\ File \\ From: \\ Yvette Peterson. Coordinator Institutional Review Board \\ Date: \\ December 18.2000 \\ Proposal Title: \\ "The Effect of Food Safety litervention on the Knowledge, Attitude and \\ Behavior of Foodservice Workers of Inner City Public School Cafeterias" \\ - Exempt $\nRightarrow 121700-01$
}

Your study was deemed exempt by the University's Institutional Review Board on December 17, 2000. There are no additional requirements in regards to your study. However, if there are changes in the protocol after you commence your study that may increase the risks that the subjects are exposed to, you are required to resubmit your proposal for review.

Plcase call the IRB office at $\mathbf{3 4 8 - 2 4 9 4}$ with questions or concems.

QUniversity Park 11200 S.W. 8 Street - PC 539

Miami, FL. 33199

(305) 348-2494 - Fax: (305) 348-4117
Division of Sponsored Research and Training

\author{
$\square$ Center for Engineering and Applied Sciences \\ 10555 West Fagler Strest - EAS 2425 \\ Miami, Fi 33174 \\ (305) 348-6439 - Fax: (305) $348-6389$
}

TDD, via FRS 1-800-955-8771 
Appendix B

Miami-Dade County Public School Board

Approval Letter To Conduct Research 


\section{MIAMI-DADE COUNTY PUBLIC SCHOOLS}

OFFICE OF EVALUATION RESEARCH 1500 BISCAYNE BOULEVARD, SUITE 225 MIAMI. FLORIDA 33132

Rooer C. Cumpas

Supenterioent of Schoots

Robert A. Collins

Enecvere Dinstor

Othe of Exwluaten and Respatc

Tax $005-7579$

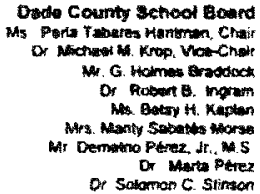

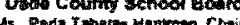
G. Hom thadoct th thaten

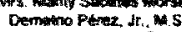
or soloman C. stimen

October 17,2000

Lillian Craggs

5200 S.W. 4 Street

Plantation, Florida 33317

Dear Ms. Craggs:

I am pleased to inform you that the Research Review Committee of the Miami-Dade County Public Schools (MDCPS) has approved your request to conduct the study, "The Effect of Food Safety Intervention on the Knowledge, Attitude and Behavior of Foodservice Workers of Inner City Public Schoot Cafeterias." The approval is granted with the following conditions:

1. Participation of a school in the study is al the discretion of the principal. A copy of this approval lefter must be presented to the principal.

2. The participation of all subjects is voluntary.

3. The anonymity and confidentiality of all subjects must be assured.

4. The study will involve approximately 60 food service workers at 4 MDCPS schools.

5. Disruption of the school's routine by the data collection activities of the study must be kept at a minimum.

It should be emphasized that the approval of the Research Review Committee does not constitute an endorsement of the study. It is simply a permission to request the voluntary cooperation in the study of individuals associated with the MDCPS. It is your responsibility to ensure that appropriate procedures are followed in requesting an individual's cooperation, and that all aspects of the study are conducted in a professional manner. With regard to the latter, make certain that all documents and instruments distributed within the MDCPS as a part of the study are caretully edited. 
The approval number for your study is 704 . This number should be used in all communications to clearly identify the study as approved by the Research Review Committee. The approval expires on June 30,2001. During the approval period, the study must adhere to the design, procedures and instruments which were submitted to the Research Review Committee. If there are any changes in the study as it relates to the MDCPS, it may be necessary to resubmit your request to the committee. Failure to notily me of such a change may result in the cancellation of the approval.

If you have any questions, please call me at (305) 995-7501. Finally, remember to forward an abstract of the study when it is complete. On behalf of the Research Review Committee, I want to wish you every success with your study.

Sincerely,

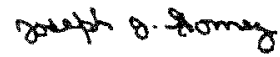

Joseph J. Gomez, Ph.D.

Chairperson

Research Review Committee

JJG:cg 
Appendix C

Letters Informing Principals of Study 


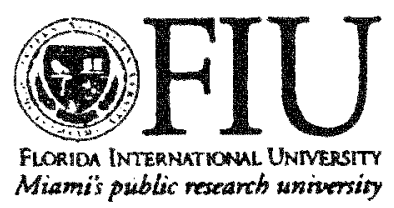

December 10, 2000

Mr. Eugene Butler

Charles Drew Middle School

$1801 \mathrm{NW} 60^{\text {th }}$ Stret

Miami, Florida 33142

\section{Dear Mr. Butler}

In collaboration with the Miami-Dade County Public Schools Department of Food and Nutrition and Florida International University, Charles Drew Middle School has been chosen to participate in a study involving food safety and foodservice employes. The title of the proposed research is: The Effect of Food Safety Intervention On The Knowledge, Attitude, and Behavior of Foodservice Workers of Imser City Public School Cafterias

As this study involves only foodservice employees of your school, no contact with students is necessary. Disnuption of daily working hours will be kept minimal while collecting data for this study, which is scheduled to begin January $11^{\text {th }}$. I will be at your school for a total of 5 visits: January $11^{\text {th }}$, January $16^{\text {th }}$, January $25^{\text {th }}$, February $5^{\text {th }}$ and February $12^{\text {th }}$. In addition, a food safety in-service training will be heid in your facility on January $26^{\text {th }}$ for foodservice personnel. This is a "reacher planning day" and no other foodservice duties will be performed on that day.

Enclosed is the letter of approval granted to us by the MDCPS Research Review Committee. Thank you for your cooperation, and if there are any questions, please contact Ms. Penny Parham, Regional Director of Regions 1, 11, and III of the Department of Food and Nutrition at 305-995-3230, Dr Dixon at Florids University at 305-348-2878 or Lillian at 954-321-8522

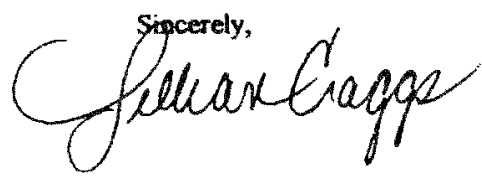

$$
\begin{gathered}
\text { College of Health and Untwan Affairs } \\
\text { School of Hedth }
\end{gathered}
$$




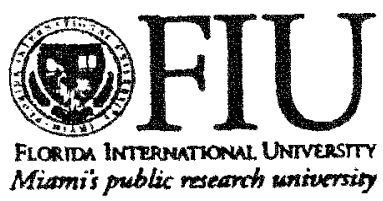

Decernber 10,2000

Ms. Linda Whye

Liberty City Elementary School

$1855 \mathrm{NW} 71^{\mathrm{m}}$ Street

Miami, Florida 33147

Dear Ms. Whye,

In collaboration with the Miani-Dade County Public Schools Department of Food and Nutrition and Florida Intermational University, Liberty City Elementary School has been chosen to participate in a study involving food safety and foodservice employees The title of the proposed research is: The Effect of Food Safety Intervention On The Knowledge, Attitude, and Behavior of Foodservice Workers of Inner City Public School Cafeterias.

As this study involves only foodservice employees of your school, no contact with students is necessary. Disnuption of daily working hours will be kept minimal while collecting data for this study, which is scheduled to begin January $11^{\text {th }}$. I will be at your school for a total of 5 visits: January $11^{\text {th }}$, January $1 t^{\text {th }}$, January $25^{\text {th }}$, February $6^{\text {th }}$ and February $12^{\text {th }}$

Enclosed is the letter of approval granted to us by the MDCPS Research Review Committee. Thank you for your cooperation, and if there are any questions, please contact Ms. Penryy Parham, Regional Director of Regions I, II, and III of the Department of Food and Nutrition at 305-995-3230, Dr Dixon at Florida University at 305-348-2878 or Lillian at 954-321-8522.
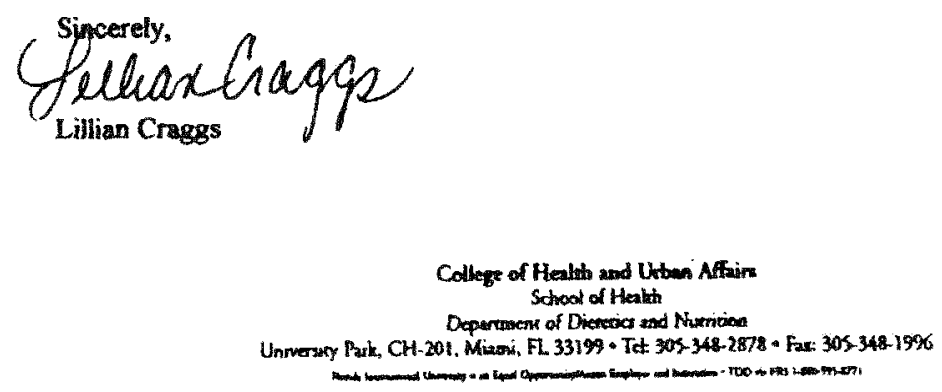


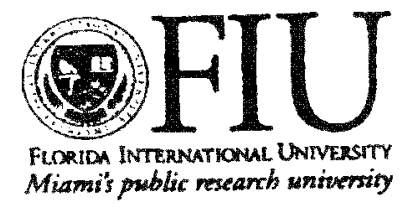

Deomber 10,2000

Ms. Cymathin Ctarke

Poincian Part Elementary School

6745 NW 23 Averue

Minni, Florida 33147

Dear Ms. Clarke,

In collaboration with the Miami-Dede County Public Schools Depertment of Food and Nutrition and Florida Intemtional University, Poincian Park Elementary Sohool has been chosen to participate in a study involving food safty and foodservioe employees. The title of the proposed rench is: The Effect of Food Sefery Intervention On The Knowledge, Attitude, and Behavior of Foodservice Workers of Imer City Public School Cafeterias.

As this study involves only foodservice employees of your school, no contact with students is necessary. Disnuption of daily working hours will be kept minimal while

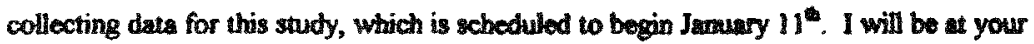
school for a total of 4 visits: January $11^{\text {th }}$, Jamuary $18^{\text {th}}$, January $25^{\text {th }}$, February 7 and February $12^{\text {th }}$.

Enclosed is the letter of approval granted to us by the MDCPS Rearch Roview Committee. Thenk you for your cooperation and if there wre any questions, please contact Ms. Perryy Parham, Regional Director of Regions I, II, and III of the Depertment of Food and Nutrition at 305-995-3230, Dr Diocon at Floride Univeruity at 305-348-2878 or Lillian af 954-321-8522.

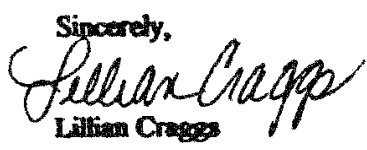

College of Heakl and Urban Nrairs Sthool of Healish 


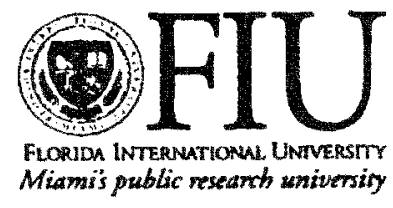

Decernber 10,2000

Ms. Dorothy Mindingall

LC. Evans Elementary School

$1895 \mathrm{NW} 75^{\text {th }}$ Street

Miami, Florida 33147

Dear Ms. Mindingali

In collaboration with the Miami-Dade County Public Schools Department of Food and Nutrition and Florida International University, LC Evans Elementary School has been chosen to participate in a study involving food safety and foodservice employees The itle of the proposed research is: The Effect of Food Safety Intervention On The Knowledge, Attitude, and Behavior of Foodservice Workers of Inner City Public School Cafeterias

As this study involves only foodservice employees of your school, no contact with students is necessary. Disruption of daily working hours will be kept minimal while collecting data for this study, which is scheduled to begin Jamary $11^{\text {th }}$. I will be at your school for a total of 5 visits: January $11^{\text {th }}$, January $19^{\text {th }}$, January $25^{\text {th }}$, February $8^{\text {th }}$ and February $12^{\text {th }}$.

Enclosed is the letter of approval granted to us by the MDCPS Research Review Committee. Thank you for your cooperation, and if there are any questions, please contact Ms. Penny Parham, Regional Director of Regions I, II, and III of the Department of Food and Nutrition at 305-995-3230, Dr Dixon at Florida University at 305-348-2878 or Lillian at 954-321-8522.

Sincerely,

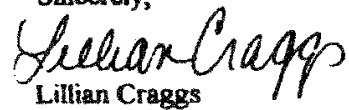

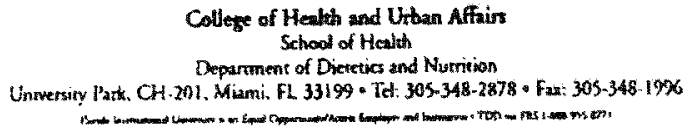


Appendix D

Fight Bac Four Simple Steps to Food Safety

Brochure 

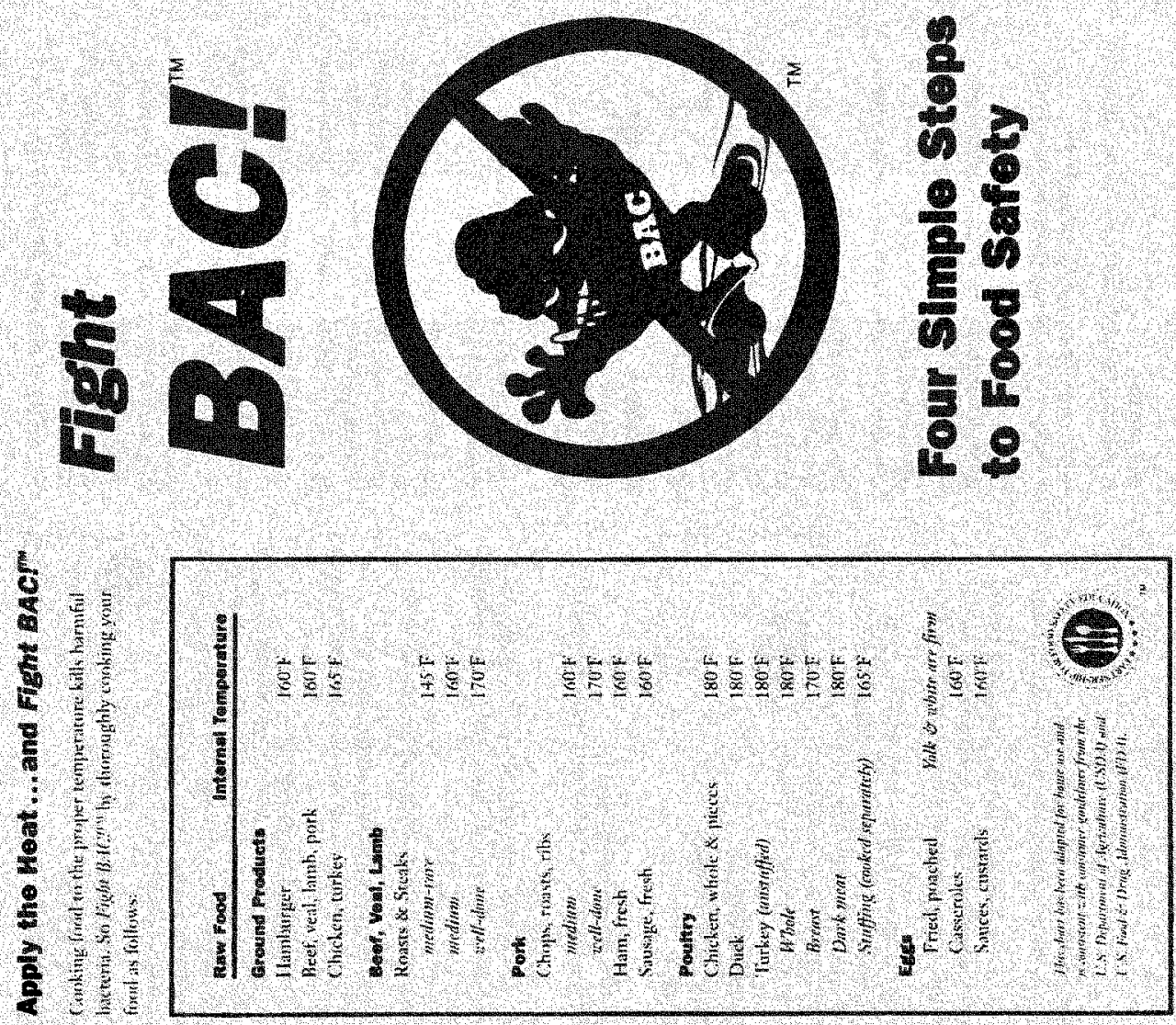

$\hat{\infty}$

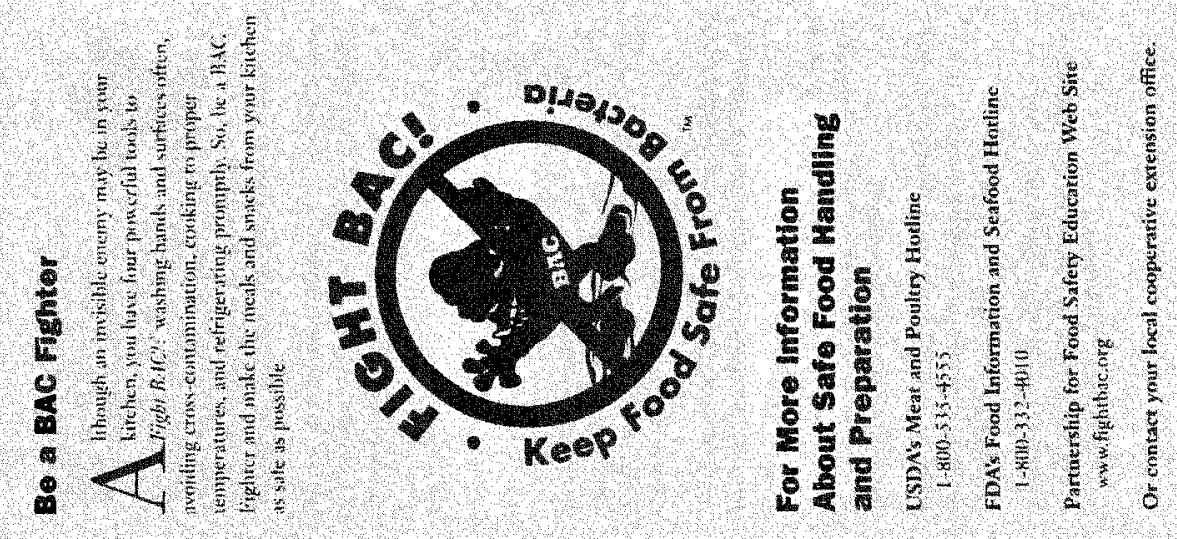



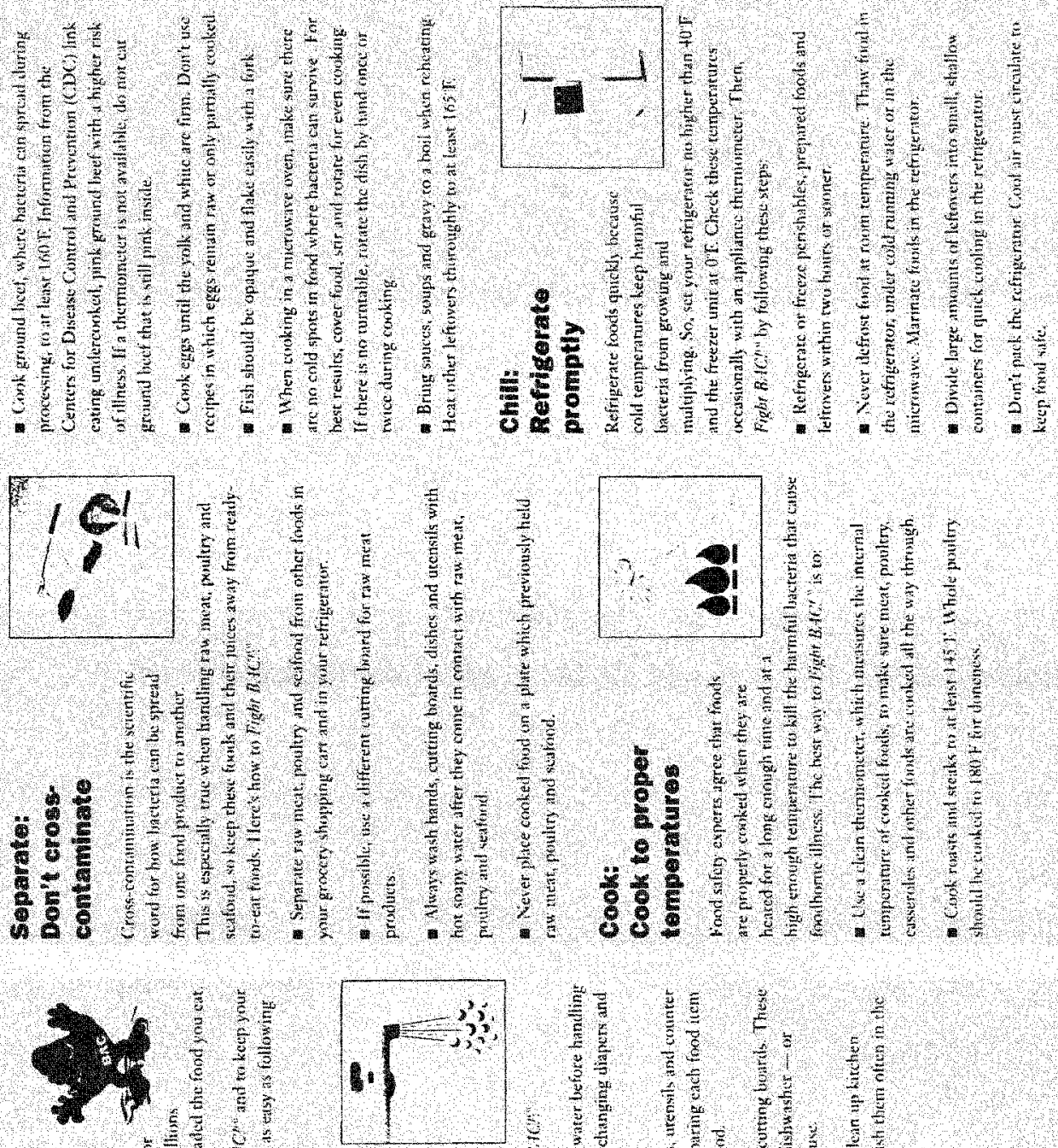

$\begin{array}{lll}2 & \end{array}$

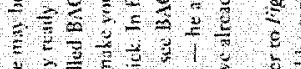

है

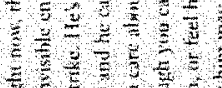

ㄴ.

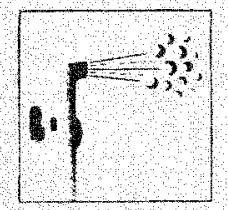

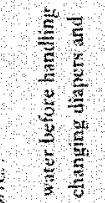

$=5, \quad \frac{1}{*}$ है

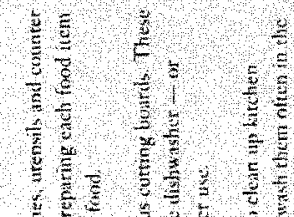

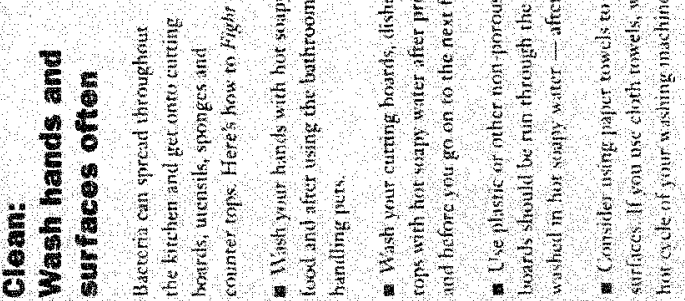




\section{Appendix E}

Food Safety Knowledge, Attitude and Behavior Questionnaire 


\section{Food Safety Questionnaire}

This questionnaire will ask a variety of questions about you and food safety. Please answer every question completely. Do not leave any question unanswered.

1) In what county do you live?
A) Broward
B) Miami-Dade
A) Male
B) Female

2) What is your gender?

3) How old are you?
A) $18-29$
B) $30-49$
C) $50+$

4) What is your date of birth?

5) Race/Ethnic Background
A) White, Not Hispanic Origin
B) Black, Not Hispanic Origin
C) Hispanic
D) American Indian/Alaskan Native
E) Asian

6) Please circle the highest grade you have completed in school

$\begin{array}{llllllllllllllll}1 & 2 & 3 & 4 & 5 & 6 & 7 & 8 & 9 & 10 & 11 & 12 & 13 & 14 & 15 & 16+\end{array}$

7) Approximately how long have you worked for Miami-Dade Public School System? years months

8) Approximately how long have you worked in foodservice for Miami-Dade Public School System? years months

9) What is your yearly salary range?
A) $\$ 1-\$ 4,999$
B) $\$ 5,000-\$ 9,999$
C) $\$ 10,000-\$ 19,999$
D) $\$ 20,000-\$ 29,999$
E) $\$ 30,000-\$ 39,999$
F) Greater than $\$ 40,000$

10) Have you ever had food safety training?
a. Yes
B. No

If yes, how long ago? years months 


\section{Food Safety Knowledge}

Please circle the correct answer. Each question requires one answer only.

11) About how many people die from food poisoning in the U.S each year?
A) less than 100
B) less than 1000
C) less than 10,000
D) more than 100,000

12) Potential hazards to food safety include:
A) physical
B) chemical
C) biological
D) all of the above

13) Examples of bacteria associated with food borne illness include:
A) Salmonella
B) E. coli 0157:H7
C) Staphylococcus aureus
D) all of the above

14) Food borne illness may be prevented by:
A) proper hand washing
B) observing proper temperatures
C) not cross contaminating
D) all of the above

15) Employees must wash their hands:
A) after using the restroom
B) after handling raw foods
C) after taking a break
D) all of the above

16) The most common ways foods become contaminated is by:
A) time/temperature abuse
B) cross contamination
C) poor personal hygiene
D) all of the above

17) An example of a physical hazard of food contamination is:
A) pesticides
B) hair
C) bacteria
D) virus

18) $90 \%$ of food borne illness arises from contamination from which hazard?
A) chemical
B) physical
C) biological
D) none of the above

19) Food intoxication may be caused by which bacteria?
A) E. coli 0157:H7
B) Staphylococcus aureus
B) Samonella
D) none of the above 
20) Botulism is caused by which bacterium?
A) Clostridium botulinum
B) E. coli 0157:H7
C) Salmonella
D) Staphylococcus aureus

21) Disposable gloves should be worn especially when:
A) touching raw meat
C) hands are dirty
B) in place of hand washing
D) handling cooked or prepared foods

22) Proper personal hygiene includes:
A) hand washing technique
B) clean uniform and hair restraint
C) going home when ill
D) all of the above

23) You are most like to get Staphyloccocal food borne illness from:
A) undercooked eggs
C) an infected cut on hand
B) raw meat and poultry
D) dented cans

24) What temperature should the refrigerator be set to?
A) 36 degrees $F$
B) 40 degrees $\mathrm{F}$
C) 45 degrees $F$
D) 50 degrees $\mathrm{F}$

25) Accurate record keeping should include daily recordings of:
A) temperature
B) time
C) date
D) all of the above

26) What is the temperature danger zone?
A) 20 to 120 degrees $\mathrm{F}$
B) 30 to 130 degrees $\mathrm{F}$
C) 40 to 140 degrees $F$
D) 50 to 150 degrees $F$

27) To what internal temperature should you cook chicken?
A) 150 degrees $\mathrm{F}$
B) 155 degrees $F$
B) 160 degrees $F$
D) 165 degrees $F$

28) To what internal temperature should you cook ground beef?
A) 150 degrees $F$
B) 160 degrees $F$
C) 170 degrees $\mathrm{F}$
D) 180 degrees $F$

29) Meat should be thawed:
A) on the counter top
B) on the top shelf of the refrigerator
C) in the sink
D) on the bottom shelf of the refrigerator

30) To take the internal temperatures of food, you should:
A) use your finger
B) taste the food
C) take a guess
D) use a calibrated thermometer 
31) Proper hand washing techniques includes using hot water and soap and lathering for how many seconds?
A) 10 seconds
B) 20 seconds
C) 30 seconds
D) 40 seconds

32) What is the best way to cool beef?
A) place on the counter top
B) keep it in the original pot
C) transfer to shallow pans
D) none of the above

33) It is acceptable to wipe hands on your apron.
A) true
B) false

34) Food borne illness is not a major concern for school foodservice.
A) true
B) false

35) The primary responsibility of food service personnel is to protect the safety of the consumer.
A) true
B) false

36) Proper hand washing technique is key to control food borne illness.
A) true
B) false

37) Uncovered hot foods will cool quicker than foods that are covered.
A) true
B) false

38) Steam tables should not be used to cook foods.
A) true
B) false

39) Time/temperature abuse is the greatest cause for food borne illness.
A) true
B) false

40) Tasting food with the cooking/serving utensil is permitted.
A) true
B) false 


\section{Food Safety Attitude}

Please put an $(\mathbf{X})$ in the box that best describes how you feel about the statement.

\begin{tabular}{|c|c|c|c|c|c|}
\hline Question & $\begin{array}{l}\text { Strongly } \\
\text { Agree }\end{array}$ & Agree & Uncertain & Disagree & $\begin{array}{l}\text { Strongly } \\
\text { Disagree }\end{array}$ \\
\hline $\begin{array}{l}\text { 1. I would always remember to } \\
\text { wash my hands after returming to } \\
\text { work from taking a break. }\end{array}$ & & & & & \\
\hline $\begin{array}{l}\text { 2. Hands should.be washed before } \\
\text { performing every foodservice duty. }\end{array}$ & & & & & \\
\hline 3. It is irmportant to wash hands. & & & & & \\
\hline $\begin{array}{l}\text { 4. Hair restraints are not necessary } \\
\text { to wear unless you are serving } \\
\text { food. }\end{array}$ & & & & & \\
\hline $\begin{array}{l}\text { 5. No one should serve or prepare } \\
\text { food if they are ill. }\end{array}$ & & & & & \\
\hline $\begin{array}{l}\text { 6. Working with open wounds, } \\
\text { bums, and abrasions is accoptable, } \\
\text { as long as the wounds aren't } \\
\text { infected. }\end{array}$ & & & & & \\
\hline $\begin{array}{l}\text { 7. A clean apron should be worn } \\
\text { daily. }\end{array}$ & & & & & \\
\hline $\begin{array}{l}\text { 8. Eating while serving/preparing } \\
\text { food is acceptable. }\end{array}$ & & & & & \\
\hline $\begin{array}{l}\text { 9. Fingernail polish is acceptable as } \\
\text { long as gloves are used while } \\
\text { serving or preparing food. }\end{array}$ & & & & & \\
\hline $\begin{array}{l}\text { 10. Bathing and wearing a clean } \\
\text { uniform should occur on a daily } \\
\text { basis. }\end{array}$ & & & & & \\
\hline $\begin{array}{l}\text { 11. As long as food is cooked, you } \\
\text { can't get sick from it. }\end{array}$ & & & & & \\
\hline $\begin{array}{l}\text { 12. I prepare food at work the same } \\
\text { way as I do at home. }\end{array}$ & & & & & \\
\hline $\begin{array}{l}\text { 13. I can always tell if food is } \\
\text { spoiled by the smell of it. }\end{array}$ & & & & & \\
\hline $\begin{array}{l}\text { 14. If a child gets diarried after } \\
\text { eating, it may be caused by the } \\
\text { foods eaten. }\end{array}$ & & & & & \\
\hline $\begin{array}{l}\text { 15. Only those persons who prepare } \\
\text { food should be concemed about } \\
\text { food safety. }\end{array}$ & & & & & \\
\hline $\begin{array}{l}\text { 16. It is unlikely that food bome } \\
\text { illness occurs in school cafeterias. }\end{array}$ & & & & & \\
\hline $\begin{array}{l}\text { 17. Safe food handling is an } \\
\text { important practice. }\end{array}$ & & & & & \\
\hline $\begin{array}{l}\text { 18. Having a thermometer in the } \\
\text { refrigerat or is unimportant as long } \\
\text { as the refrigerator foels cold. }\end{array}$ & & & & & \\
\hline $\begin{array}{l}\text { 19. I observe safe food handling } \\
\text { practices all the time. }\end{array}$ & & & & & \\
\hline $\begin{array}{l}\text { 20. I understand the importance of } \\
\text { safe food handling. }\end{array}$ & & & & & \\
\hline
\end{tabular}


Food Safety Behavior

Please put an $(\mathbf{X})$ in the box that best describes your actions.

\begin{tabular}{|c|c|c|c|c|c|}
\hline Question & $\begin{array}{l}\text { Strongly } \\
\text { Agree }\end{array}$ & Agree & Uncertain & Disagree & $\begin{array}{l}\text { Strongly } \\
\text { Disagree }\end{array}$ \\
\hline $\begin{array}{l}\text { 1. When preparing food, I } \\
\text { separate raw meat/poultry } \\
\text { from other food. }\end{array}$ & & & & & \\
\hline $\begin{array}{l}\text { 2. I serve, reheat or freeze } \\
\text { food within } 2 \text { hours of } \\
\text { purchase. }\end{array}$ & & & & & \\
\hline $\begin{array}{l}\text { 3. I use a calibrated } \\
\text { thermometer to verify that } \\
\text { food is cooked to a safe } \\
\text { temperature. }\end{array}$ & & & & & \\
\hline $\begin{array}{l}\text { 4. I wash hands after handling } \\
\text { raw meat or poultry. }\end{array}$ & & & & & \\
\hline $\begin{array}{l}\text { 5. I wash hands after retuming } \\
\text { to work from a break. }\end{array}$ & & & & & \\
\hline 6. I come to work when ill. & & & & & \\
\hline $\begin{array}{l}\text { 7. I use different spoons when } \\
\text { tasting, cooking and serving } \\
\text { food. }\end{array}$ & & & & & \\
\hline $\begin{array}{l}\text { 8. I use clean and sanitized } \\
\text { equipment, utensils and } \\
\text { countertops before preparing } \\
\text { food. }\end{array}$ & & & & & \\
\hline $\begin{array}{l}\text { 9. I don't always wear hair } \\
\text { restraints while preparing or } \\
\text { serving food. }\end{array}$ & & & & & \\
\hline $\begin{array}{l}10 . \text { I use a thermometer to } \\
\text { verify that cooked food is held } \\
\text { above } 140 \text { degrees } F \text { or below } \\
40 \text { degrees } F \text {. }\end{array}$ & & & & & \\
\hline $\begin{array}{l}\text { 11. I repackage leftover food } \\
\text { into smaller containers. }\end{array}$ & & & & & \\
\hline $\begin{array}{l}\text { 12. I prepare food at work the } \\
\text { same way as I do at home. }\end{array}$ & & & & & \\
\hline
\end{tabular}




\section{Appendix F}

Schedule of Events Given to Foodservice Managers in Study 


\section{Charles Drew Middle School}

Important dates to remember:

January 16-22 ${ }^{\text {nd }}$ : Time/Temperature Chart Recordings

January $16^{\text {th }}$ : Pre-inspection and Pre-test

January $25^{\text {th }}$ : Collect Time/Temperature Recordings

February 5-9 ${ }^{\text {th }}$ : Time/Temperature Recordings

February $5^{\text {th }}$ : Post-inspection and Post-test

February $12^{\text {th }}$ : Collect Time/Temperature Charts 


\section{Liberty City Elementary School}

Important dates to remember:

January 16-22 ${ }^{\text {nd }}$ : Time/Temperature Chart Recordings

January $17^{\text {th }}:$ Pre-inspection and Pre-test

January $25^{\text {th }}$ : Collect Time/Temperature Recordings

$* * * * *$ January $26^{\text {th }}$ : Food safety and sanitation in-service 8:00 AM at Liberty City Elementary School Auditorium

February 5-9 ${ }^{\text {th }}$ : Time/Temperature Recordings

February $6^{\text {th }}$ : Post-inspection and Post-test

February $12^{\text {th }}$ : Collect Time/Temperature Charts 


\section{Poinciana Park Elementary School}

Important dates to remember:

January 16-22 ${ }^{\text {nd }}$ : Time/Temperature Chart Recordings

January $18^{\text {th }}$ : Pre-inspection and Pre-test

January $25^{\text {th }}$ : Collect Time/Temperature Recordings

$* * * * *$ January $26^{\text {th }}$ : Food safety and sanitation in-service 8:00 AM at Liberty City Elementary School Auditorium

February 5-9 ${ }^{\text {th }}$ : Time/Temperature Recordings

February $7^{\text {th }}:$ Post-inspection and Post-test

February $12^{\text {th }}$ : Collect Time/Temperature Charts 


\section{Lillie C Evans Elementary School}

Important dates to remember:

January 16-22 ${ }^{\text {nd }}$ : Time/Temperature Chart Recordings

January $19^{\text {th }}$ : Pre-inspection and Pre-test

January $25^{\text {th }}$ : Collect Time/Temperature Recordings

$* * * * *$ January $26^{\text {th }}$ : Food safety and sanitation in-service 8:00 AM at Liberty City Elementary School Auditorium

February 5-9 ${ }^{\text {th }}$ : Time/Temperature Recordings

February $8^{\text {th }}$ : Post-inspection and Post-test

February $12^{\text {th }}:$ Collect Time/Temperature Charts 
Appendix G

Script Explaining Objectives of Research Study 


\section{The Effect of Food Safety Education On The Knowledge, Attitude and Behavior of Foodservice Workers of Inner City Public Schools}

You are being asked to participate in a research study conducted by Florida International University. I hope to learn what the knowledge, attitude and behaviors are of foodservice workers who are employed at public school cafeterias in the inner city of Miami.

If you decide to volunteer, you will be asked to answer a food safety questionnaire at two differing times (pre and post-test) at the end of your work shift that will ask questions about your demographics, food safety knowledge, attitude and behavior towards practicing safe food handling. This will take you approximately 45 minutes to complete. You will also be asked to attend a food safety in-service training that will take place at Liberty City Elementary School at 8:00 am on January 26, 2001. This will take place on a "teacher's planning day", a scheduled day off for foodservice, so you will not be required to perform your work duties on that day. You would be required to make your own travel arrangements to the in-service. The duration of the in-service will take approximately 3 hours.

There are no known risks involved in your being in this study. Since food safety training is a requirement of the normal employment conditions with Miami-Dade County Public Schools, this in-service will provide a structured aspect to this requirement. However, if you choose not to participate, this will not affect your employment status or be used negatively against you in any way.

All answers to questionnaires and any other information gathered for this study will be kept confidential. The faculty supervisor and myself will only have access to this information.

You will be paid monetarily by your employer, Miami-Dade County Public Schools, for attending this food safety training on your usually scheduled day off. Since the questionnaires will be distributed at the end of your work shift, you will also be paid for any time spent answering this questionnaire.

If at any time you decide not to participate in this study, you have the right to refuse without having any negative consequences. It will not affect your employment status with Miami-Dade County Public Schools in any way.

If you have any questions now please ask me. If you have any questions later, the faculty supervisor or I may be reached at: Lillian Craggs or Dr. Zisca Dixon at 305-348-2878.

Your attendance to the in-service and voluntary response to taking the questionnaire indicates an agreement to participate. 
Appendix $\mathrm{H}$

Facility Inspection Form 


\section{Food Safety Inspection Checklist}

Place designated score to the right on the appropriate item:

$$
\begin{aligned}
& 1=\text { Yes } \\
& 2=\text { No } \\
& 3=\text { Not Applicable }
\end{aligned}
$$

Date:

Time:

Facility:

Food Safety

1. Is food free of visible spoilage?

Comments:

2. Are food packages free from rips, dents and damage?

Comments:

3. Is food properly labeled and stored?

Comments:

\section{Food Protection}

1. Are refrigerators/freezers/dry storage at proper temperature?

Comments:

2. Are thermometers provided and conspicuously displayed?

Comments: 
3. Is food protection observed during storage?

Comments:

4. Is food protection observed during preparation?

Comments:

5. Is food protection observed during display?

Comments:

6. Is food protection displayed during serving?

Comments:

Food Equipment and Utensils

1. Are food dispensing utensils properly stored?

Comments:

2. Are food contact surfaces of equipment clean?

Comments:

3. Are food contact surfaces on preparation counters clean?

Comments: 
4. Is dishwashing facility maintained?

Comments:

5. Are food trays and eating supplies clean?

Comments:

6. Is there proper storage for wiping cloths and cleaning supplies?

Comments:

\section{Personnel}

1. Are those personnel with visible infections restricted from food handling?

Comments:

2. Are clean uniforms being worn?

Comments:

3. Are employees wearing hair restraints?

Comments:

4. Are disposable gloves being worn appropriately?

Comments: 
5. Are employees practicing hands washing?

Comments:

6. Are good hygienic practices being observed?

Comments:

\section{Toilet and Hand Washing Facility}

1. Are the facilities convenient and accessible?

\section{Comments:}

2. Are the facilities clean?

Comments:

3. Is hot/cold water plumbing provided?

\section{Comments:}

4. Is hand sanitation soap provided?

\section{Comments:}

5. Are disposable hand drying towels provided?

Comments: 


\section{Garbage and Refuse Disposal}

1. Are receptacles clean with appropriate liner?

Comments:

2. Is placement safely away from food preparation and serving?

Comments:

3. Are they adequate and not overflowing?

Comments:

\section{Floors, Walls, Ceilings, Lighting and Ventilation}

1. Are floors clean and safe from slipping and tripping?

Comments:

2. Are walls and ceilings surfaces clean?

Comments:

3. Are rooms properly lighted and ventilated?

Comments: 
Appendix I

Time/Temperature Record Form 


\section{Time/Temperature Evaluation}

\section{Instructions:}

1. Record date and circle day of week evaluation performed.

2. Do not remove cover/lids on foods until you are ready to take temperature.

3. Take temperatures of cold items first, followed by each hot item.

4. Insert thermometer into the center of each serving and hold until indicator comes to rest.

5. Record temperature of each item as it is taken.

6. Record times appropriately.

\begin{tabular}{|l|l|l|l}
\hline Date: $/ 2001$ & Day: M T W TH F & Meal: Breakfast/Lunch \\
\hline
\end{tabular}

\begin{tabular}{|c|c|c|c|c|c|}
\hline $\begin{array}{l}\text { Menu } \\
\text { Item }\end{array}$ & $\begin{array}{l}\text { Cooking } \\
\text { Endpoint } \\
\text { Temperature } \\
\text { Degrees F }\end{array}$ & $\begin{array}{l}\text { Cooking } \\
\text { Completion } \\
\text { Time }\end{array}$ & $\begin{array}{l}\text { Holding } \\
\text { Temperature } \\
\text { Degrees F }\end{array}$ & Serving Time & $\begin{array}{l}\text { Serving } \\
\text { Temperature } \\
\text { Degrees F }\end{array}$ \\
\hline $\begin{array}{l}\text { Cold } \\
\text { Entree }\end{array}$ & & & & & \\
\hline $\begin{array}{l}\text { Hot } \\
\text { Entree }\end{array}$ & & & & & \\
\hline Milk & & & & & \\
\hline $\begin{array}{l}\text { Starch } \\
\text { (Rice, } \\
\text { Pasta or } \\
\text { Potato } \\
\text { Other } \\
\text { Than } \\
\text { Entree) }\end{array}$ & & & & & \\
\hline $\begin{array}{l}\text { Vege- } \\
\text { table }\end{array}$ & & & & & \\
\hline $\begin{array}{l}\text { Fruit or } \\
\text { Fruit } \\
\text { Juice }\end{array}$ & & & & & \\
\hline Dessert & & & & & \\
\hline
\end{tabular}


Appendix $\mathbf{J}$

Miami-Dade County Public Schools

Refrigerator and Freezer Record Form 
Depariment of Food and Nutrition

Miami-Dade County Public Schools

\section{DAILX TEMPERATURE RECORD}

FOR THE MONTH OF

20

SCHOOL LOC."

\begin{tabular}{|c|c|c|c|c|c|c|c|c|c|c|c|c|c|c|c|c|c|c|c|}
\hline \multirow{2}{*}{ DAY } & \multirow[b]{2}{*}{ TIMEE } & \multirow[b]{2}{*}{ NAME } & \multicolumn{5}{|c|}{ REFRIGERATOR } & \multicolumn{2}{|c|}{$\begin{array}{c}\text { WALK - } \\
\text { IN }\end{array}$} & \multicolumn{4}{|c|}{ MILKROX } & \multicolumn{5}{|c|}{ FREEZER } & \multirow[b]{2}{*}{ SRY } \\
\hline & & & 1 & 2 & 3 & 4 & 5 & $\mathbf{R}$ & $F$ & 1 & 2 & 3.1 & 4 & i & 2 & 3 & 43 & 5 & \\
\hline 1 & & & & & & & & & & & & & & & & & & & \\
\hline 2 & & & & & & & & & & & & & & & & & & & \\
\hline 3 & & & & & & & & & & & & & & & & & & & \\
\hline 4 & & & & & & & & & & & & & & & & & & & \\
\hline 5 & & & & & & & & & & & & & & & & & & & . \\
\hline 6 & & & & & 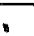 & & & & & & & & & & & & & & \\
\hline 7 & & & & & & & & & & & & & & & & & & & 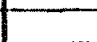 \\
\hline 8 & & & & & & & & & & & & & & & & & & & 1 \\
\hline 9 & & & & & & & & & & & & & & & & & & & \\
\hline 10 & & & & & & & & & & & & & & & & & & & \\
\hline II & & & & & & & & & & & & & & & & & & & \\
\hline 12 & & & & & & & & & & & & & & & & & & & \\
\hline 13 & & & & & & & & & & & & & & & & & & & \\
\hline 14 & & & & & & & & & & & & & & & & & & & \\
\hline 15 & & & & & & & & & & & & & 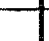 & & & & & & \\
\hline 16 & & & & & & & & & & & & & & & & & & & \\
\hline 17 & & & & & & & & & & & & & & & & & & & \\
\hline 18 & & & & & & & & & & & & & & & & & & & \\
\hline 19 & & & & & & & & & & & & & & & & & & & \\
\hline 20 & & & & & & & & & & & & & + & & & & & & \\
\hline 21 & & & & & & & & & & & & & & & & & & & \\
\hline 22 & & & & & & & & & & & & & & & & & & & \\
\hline 23 & & & & & & & & & & & & & & & & & & & \\
\hline 24 & & & & & & & & & & & & & & & & & & & \\
\hline 25 & & & & & & & & & & & & & & & & & & & \\
\hline 26 & & & & & & & & & & & & & 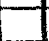 & & & & & & \\
\hline 27 & & & & & & & & & & & & & & & & & & & \\
\hline 28 & & & & & & & & & & & & & & & & & & & \\
\hline 29 & & & & & & & & & & & & & & & & & & & \\
\hline 30 & & & & & & & & & & & & & & & & & & & \\
\hline 31 & & & & & & & & & & & & & & & & & & & \\
\hline
\end{tabular}

$7 / 11 / 00 \mathrm{~mm}$ 
Appendix K

Food Safety Training In-Service

Evaluation Form 


\section{In-Service Evaluation}

Please place the letter of the response that best describes your reaction to this in-service. Use the comment section to add any additional suggestions you might have.

$$
\begin{aligned}
& A=\text { Agree } \\
& D=\text { Disagree }
\end{aligned}
$$

1. The objectives were clearly defined

2. The objectives were met at the end of the in-service

3. The presenter was well-organized

4. The presenter was enthusiastic about the material presented

5. The presenter was knowledgeable about the material presented

6. The videotapes were interesting

7. The demonstration was helpful

8. I enjoyed this in-service

9. This in-service taught the importance of safe food handling

10. I will practice safe food handling techniques learned from this in-service training

\section{Comments:}


Appendix L

Food Safety Training In-Service

Attendance Sign-In Form 
Food Safety Training Attendance January 26, 2001

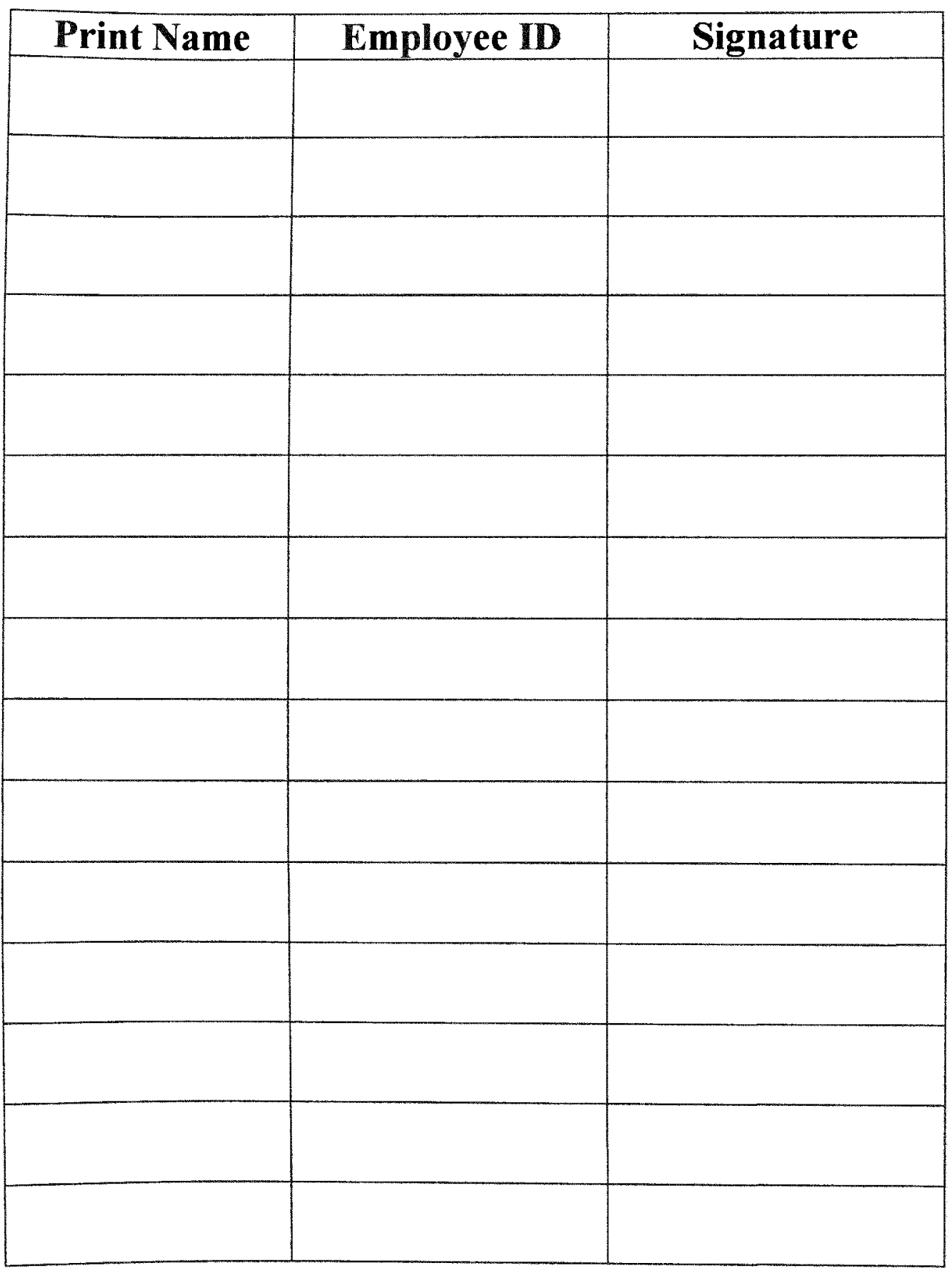

Time Begin: Time End: 